\title{
Differential Alterations of the Mitochondrial Morphology and Respiratory Chain Complexes during Postnatal Development of the Mouse Lung
}

\author{
Natalia El-Merhie, ${ }^{1}$ Eveline Baumgart-Vogt, ${ }^{1}$ Adrian Pilatz, ${ }^{2}$ Susanne Pfreimer, ${ }^{1}$ \\ Bianca Pfeiffer, ${ }^{1}$ Oleg Pak, ${ }^{3}$ Djuro Kosanovic, ${ }^{3}$ Michael Seimetz, ${ }^{3}$ Ralph Theo Schermuly, ${ }^{3}$ \\ Norbert Weissmann, ${ }^{3}$ and Srikanth Karnati ${ }^{1}$ \\ ${ }^{1}$ Institute for Anatomy and Cell Biology II, Division of Medical Cell Biology, Justus Liebig University, Giessen, Germany \\ ${ }^{2}$ Department of Urology, Pediatric Urology and Andrology, Justus Liebig University, Giessen, Germany \\ ${ }^{3}$ Excellence Cluster Cardio-Pulmonary System (ECCPS), German Lung Center (DZL), \\ Universities of Giessen and Marburg Lung Center (UGMLC), Justus Liebig University, Giessen, Germany
}

\begin{abstract}
Correspondence should be addressed to Eveline Baumgart-Vogt; eveline.baumgart-vogt@anatomie.med.uni-giessen.de and Srikanth Karnati; srikanth.karnati@anatomie.med.uni-giessen.de
\end{abstract}

Received 21 August 2017; Accepted 28 September 2017; Published 19 December 2017

Academic Editor: Liang-Jun Yan

Copyright (c) 2017 Natalia El-Merhie et al. This is an open access article distributed under the Creative Commons Attribution License, which permits unrestricted use, distribution, and reproduction in any medium, provided the original work is properly cited.

\begin{abstract}
Mitochondrial biogenesis and adequate energy production in various organs of mammals are necessary for postnatal adaptation to extrauterine life in an environment with high oxygen content. Even though transgenic mice are frequently used as experimental models, to date, no combined detailed molecular and morphological analysis on the mitochondrial compartment in different lung cell types has been performed during postnatal mouse lung development. In our study, we revealed a significant upregulation of most mitochondrial respiratory complexes at protein and mRNA levels in the lungs of P15 and adult animals in comparison to newborns. The majority of adult animal samples showed the strongest increase, except for succinate dehydrogenase protein (SDHD). Likewise, an increase in mRNA expression for mtDNA transcription machinery genes (Polrmt, $T f a m, T f b 1 m$, and $T f b 2 m$ ), mitochondrially encoded RNA ( $m t-R n r 1$ and mt-Rnr2), and the nuclear-encoded mitochondrial DNA polymerase (POLG) was observed. The biochemical and molecular results were corroborated by a parallel increase of mitochondrial number, size, cristae number, and complexity, exhibiting heterogeneous patterns in distinct bronchiolar and alveolar epithelial cells. Taken together, our results suggest a specific adaptation and differential maturation of the mitochondrial compartment according to the metabolic needs of individual cell types during postnatal development of the mouse lung.
\end{abstract}

\section{Introduction}

Mitochondria, commonly referred to as the "powerhouse" of the cell, are involved in energy production, $\beta$-oxidation of fatty acids, calcium buffering, cell signaling, proliferation and apoptosis, embryonic development, and general body ageing $[1,2]$. Structurally, mitochondria differ from other cell organelles by possessing four distinct membrane compartments: the outer mitochondrial membrane (OMM), the intermembrane space (IMS), the inner mitochondrial membrane (IMM) that forms invaginations called cristae, and the matrix $[3,4]$. The most important role of mitochondria is the production of nicotinamide adenine dinucleotide (NADH) and adenosine triphosphate (ATP) [5-7]. The respiratory chain, comprising five protein complexes and residing in the inner mitochondrial membrane (IMM), is responsible for the generation of ATP by oxidative phosphorylation (OXPHOS) [8]. Five respiratory chain complexes are known as complex I (NADH-coenzyme Q oxidoreductase), complex II (succinate-coenzyme Q oxidoreductase), complex III (coenzyme Q-cytochrome c oxidoreductase), complex IV (cytochrome c oxidase), and complex V (ATP 
synthase) [9]. Most OXPHOS complexes are encoded by both mitochondrial and nuclear subunits with the exception of complex II, which is solely encoded by nuclear genes [10]. Moreover, mitochondria contain in their matrix a circular genome (mtDNA) that is essential for their function in oxidative phosphorylation. The mtDNA encodes 13 polypeptides of complexes I, III, IV, and V, 2 ribosomal RNAs, and 22 tRNAs [11].

Mitochondrial metabolic pathways are interlinked, and the whole mitochondria interact with other organelles, such as the endoplasmic reticulum and peroxisomes, facilitating intracellular/interorganellar communication and influencing cellular metabolic functions $[12,13]$. The mitochondrial membrane potential is essential for the normal functioning of the mitochondrial respiratory chain, in which even under physiological conditions reactive oxygen species (ROS) are released [14]. Under pathological conditions, higher generation of ROS $\left(\mathrm{H}_{2} \mathrm{O}_{2}\right)$ combined with NO leads to the production of peroxynitrite $\left(\mathrm{ONOO}^{-}\right)$or other RNS species $[15,16]$. Higher NO levels impair mitochondrial respiration and membrane potential and inhibit superoxide dismutase (SOD2), leading to a higher superoxide release $[17,18]$. To combat higher generation of ROS, mitochondria employ a complex network of enzymatic and nonenzymatic defense systems. These antioxidant systems include enzymes localized within the mitochondrial matrix such as manganesecontaining superoxide dismutase (MnSOD), glutathione peroxidase (GPx), glutathione reductase (GR), thioredoxin II (Trx II), and peroxiredoxins I and III (Prxs I and III) as well as the enzymes localized within the mitochondrial intermembrane space such as copper/zinc (Cu/Zn) SOD [19-23]. Mitochondria are also involved in acetyl-CoA production and in calcium metabolism $[24,25]$.

Many energy-demanding physiological processes are initiated at birth, leading to the modification of the metabolic pathways important for energy production. This modification, which triggers the switch from glycolysis to respiration, depends on the maturation of mitochondria [26, 27]. It is known that the acquirement of functional mitochondria after birth is an important homeostatic process allowing newborn mammals to adapt for the extrauterine life in an environment with high oxygen levels. Therefore, the induction of many mitochondrial enzymes occurs during the first hours of postnatal life [28]. Further, during postnatal lung development also, mitochondria of nonciliated bronchiolar epithelial cells and type II alveolar epithelial cells (AECII) undergo extensive remodeling by significant alterations in their morphological appearance (volume density, size, number, and distribution) [29-32].

It is becoming increasingly clear that mitochondrial dysfunction may promote or predispose to the onset of lung diseases. Indeed, mitochondrial dysfunction with reduced levels of respiratory complexes has been shown in COPD and non-COPD smokers as well as in bronchial epithelial cells in mice suffering from asthma [33-38]. Given the extensive usage of wild-type and various genetically modified mice to understand the pathophysiological changes, it is essential to investigate mitochondrial biogenesis, metabolism, and maturation during regular postnatal lung development of wild-type mice. However, to date, no detailed combined molecular and morphological analysis has been performed on the mitochondrial compartment during postnatal development of the mouse lung. Postnatal alterations of the mitochondrial compartment and its respiratory function have been mainly described in rat liver and muscle [28, 39-44], pig skeletal muscle [45], rat, rabbit, and bovine hearts [43, 46-49], mouse blood lymphocytes [50], and rat and mouse brain [51-53]. Therefore, here, we analyzed mitochondrial alterations during postnatal development (newborn, P15, and adult) of the mouse lung. Our results revealed an upregulation of most mitochondrial complexes (complexes I, III, IV, and V) at the protein and the mRNA levels in the lung tissue samples of P15 and adult in comparison to newborn mice. These results were corroborated by the upregulation of mRNAs for mtDNA transcription machinery genes, mitochondrially encoded RNA, and mitochondrial DNA polymerase from the lungs of the P15 and adult mice in comparison to the lungs of the newborn mice. Interestingly, a clear difference was observed in the SDHD protein abundance pattern that peaked in the lungs of P15 animals and then decreased in the adult animals.

\section{Materials and Methods}

2.1. Experimental Animals. Three groups of C57BL/6J mice with different postnatal ages were used in this study: eighteen newborn pups (P0.5) of four pregnant dames as well as 18 male mice ( 9 mice at postnatal day and 15 and 9 adult mice at 12 weeks of age). The mice were obtained from Charles River (Sulzfeld, Germany) and were housed after the delivery in cages at the central animal facility (Zentrales Tierlabor (ZTL)) of the Justus Liebig University (Giessen, Germany). They were maintained under standard environmental conditions with a 12-hour light/dark cycle at $23^{\circ} \mathrm{C} \pm 1^{\circ} \mathrm{C}$ and $55 \% \pm 1 \%$ relative humidity. Animals had access to normal laboratory diet and food ad libitum. All animal experiments in this study were approved by the German Government Commission of Animal Care (Regierungspraesidium Giessen, Germany, permit number V 54-19 C 20/15 c GI 20/23).

\subsection{Perfusion Fixation, Sampling, and Tissue Processing for} Routine Transmission Electron Microscopy (TEM). The detailed protocol for perfusion fixation with a $1.5 \%$ paraformaldehyde (PFA)/1.5\% glutaraldehyde (GA) in $0.15 \mathrm{M}$ HEPES buffer ( $\mathrm{pH} 7.4$ ), sampling, and tissue processing of lungs for routine transmission electron microscopy (TEM) was described previously [54]. Fixed lung tissue blocks of $1 \mathrm{~mm}^{3}$ of the newborn, P15, and adult animals were embedded into the epoxid Agar 100 Resin ${ }^{\circledR}$ (Agar, Essex, England) and polymerized for 3 days at $60^{\circ} \mathrm{C}$. Embedded tissue blocks were trimmed with a diamond trimmer (Reichert TM 60, Austria), and then ultrathin sections $(80 \mathrm{~nm})$ were cut with a Leica Ultracut E ultramicrotome (Leica, Nussloch, Germany). The cut sections were contrasted with uranyl acetate ( $2 \mathrm{~min}$ ) and lead citrate ( $45 \mathrm{~s}$ ) and thereafter examined with a LEO 906 transmission electron microscope (LEO Electron 
TABLE 1: List of primary and secondary antibodies used in this study.

\begin{tabular}{|c|c|c|c|c|c|c|c|}
\hline Primary antibody against antigen & Symbol & Host & Company & $\begin{array}{c}\text { Cat. } \\
\text { number }\end{array}$ & $\begin{array}{l}\text { Dilution } \\
\text { (WB) }\end{array}$ & $\begin{array}{l}\text { Dilution } \\
\text { (IF) }\end{array}$ & $\begin{array}{c}\text { Dilution } \\
\text { (IEM) }\end{array}$ \\
\hline \multicolumn{8}{|l|}{ Mitochondrial proteins } \\
\hline $\begin{array}{l}\text { NADH:ubiquinone oxidoreductase core subunit } 1 \\
\text { (complex I) }\end{array}$ & MT-ND1 & $\begin{array}{l}\text { Rabbit, } \\
\text { polyclonal }\end{array}$ & Abcam & ab74257 & $1: 500$ & - & - \\
\hline $\begin{array}{l}\text { Succinate dehydrogenase complex subunit D } \\
\text { (complex II) }\end{array}$ & $\begin{array}{l}\text { SDHD, } \\
\text { CybS }\end{array}$ & $\begin{array}{l}\text { Rabbit, } \\
\text { polyclonal }\end{array}$ & Millipore & ABT110 & $1: 3000$ & - & $1: 50$ \\
\hline OXPHOS complex III core 2 subunit (complex III) & UQCR2 & $\begin{array}{l}\text { Mouse, } \\
\text { monoclonal }\end{array}$ & Invitrogen & A11143 & - & $1: 250$ & - \\
\hline $\begin{array}{l}\text { OXPHOS complex IV subunit I/cytochrome c } \\
\text { oxidase I (complex IV) }\end{array}$ & $\begin{array}{l}\text { COX1, } \\
\text { MT-CO1 }\end{array}$ & $\begin{array}{l}\text { Mouse, } \\
\text { monoclonal }\end{array}$ & Invitrogen & 459600 & $1: 1000$ & - & $1: 100$ \\
\hline $\begin{array}{l}\text { OXPHOS complex IV subunit II/cytochrome c } \\
\text { oxidase II (complex IV) }\end{array}$ & $\begin{array}{l}\mathrm{COX} 2 \\
\mathrm{MT}-\mathrm{CO} 2\end{array}$ & $\begin{array}{l}\text { Mouse, } \\
\text { monoclonal }\end{array}$ & Invitrogen & A6404 & $1: 1000$ & - & - \\
\hline $\begin{array}{l}\text { ATP synthase, } \mathrm{H}^{+} \text {transporting mitochondrial F1 } \\
\text { complex, beta subunit (complex V) }\end{array}$ & ATP5b & $\begin{array}{l}\text { Mouse, } \\
\text { monoclonal }\end{array}$ & $\begin{array}{c}\text { Life } \\
\text { Technologies }\end{array}$ & A21351 & $1: 3000$ & - & - \\
\hline ATP synthase 6 (complex V) & $\begin{array}{l}\text { MT- } \\
\text { ATP6E }\end{array}$ & $\begin{array}{c}\text { Rabbit, } \\
\text { polyclonal }\end{array}$ & Santa Cruz & Sc-20946 & - & - & $1: 50$ \\
\hline $\begin{array}{l}\text { Polymerase (DNA) gamma } 2, \\
\text { accessory subunit }\end{array}$ & POLG2 & $\begin{array}{l}\text { Mouse, } \\
\text { polyclonal }\end{array}$ & Abcam & ab66961 & $1: 1000$ & - & - \\
\hline Mitochondrial transcription factor A & TFAM & $\begin{array}{l}\text { Goat, } \\
\text { polyclonal }\end{array}$ & Santa Cruz & Sc- 19050 & - & - & - \\
\hline \multicolumn{8}{|l|}{ Cell-specific markers } \\
\hline Prosurfactant protein C & Pro-SP-C & $\begin{array}{l}\text { Rabbit, } \\
\text { polyclonal }\end{array}$ & Chemicon & ab3786 & - & $1: 1000$ & - \\
\hline Club cell protein $10(\mathrm{CC} 10)$ & $\mathrm{CC} 10$ & $\begin{array}{l}\text { Rabbit, } \\
\text { polyclonal }\end{array}$ & Santa Cruz & sc- -25555 & - & $1: 1000$ & - \\
\hline \multicolumn{8}{|l|}{ Loading control } \\
\hline Glyceraldehyde 3-phosphate dehydrogenase & GAPDH & $\begin{array}{l}\text { Mouse, } \\
\text { monoclonal }\end{array}$ & $\begin{array}{l}\text { HyTest, } \\
\text { Finland }\end{array}$ & $5 \mathrm{G} 4$ & $1: 8000$ & - & - \\
\hline \multicolumn{8}{|l|}{ Secondary antibodies } \\
\hline Fab anti-rabbit IgG ultrasmall gold & - & Goat & Aurion & 800.255 & - & - & $1: 400$ \\
\hline Fab anti-mouse IgG ultrasmall gold & & Goat & Aurion & 800.266 & - & - & $1: 400$ \\
\hline Anti-rabbit-IgG Alexa Fluor 488 & - & Donkey & $\begin{array}{c}\text { Life } \\
\text { Technologies }\end{array}$ & A21206 & - & $1: 1000$ & - \\
\hline Anti-mouse-IgG Alexa Fluor 555 & - & Donkey & $\begin{array}{c}\text { Life } \\
\text { Technologies }\end{array}$ & A31570 & - & $1: 1000$ & - \\
\hline Anti-rabbit-IgG alkaline phosphatase conjugate & - & $\begin{array}{c}\text { Goat, } \\
\text { polyclonal }\end{array}$ & $\begin{array}{l}\text { Sigma- } \\
\text { Aldrich }\end{array}$ & A0545 & $1: 20,000$ & - & - \\
\hline Anti-mouse-IgG alkaline phosphatase conjugate & - & $\begin{array}{l}\text { Goat, } \\
\text { polyclonal }\end{array}$ & $\begin{array}{l}\text { Sigma- } \\
\text { Aldrich }\end{array}$ & A3562 & $1: 20,000$ & - & - \\
\hline \multicolumn{8}{|l|}{ Counterstaining of nuclei for immunofluorescence } \\
\hline Hoechst $33342(1 \mu \mathrm{g} / \mathrm{ml})$ & - & - & $\begin{array}{c}\text { Life } \\
\text { Technologies }\end{array}$ & 33342 & - & $1: 1000$ & - \\
\hline TOTO $^{\circledR}-3$ iodide & - & - & $\begin{array}{c}\text { Life } \\
\text { Technologies }\end{array}$ & $\mathrm{T}-3604$ & - & $1: 1000$ & - \\
\hline
\end{tabular}

Microscopy, Oberkochen, Germany) equipped with a 2kcamera (TRS, Troendle systems).

2.3. Postembedding Immunoelectron Microscopy of Mitochondrial Proteins. The detailed protocol for perfusion fixation with $4 \%(w / v)$ paraformaldehyde (PFA)/0.05\% $(v / v)$ glutaraldehyde (GA)/PBS, processing of lungs, embedding into LR white was described previously [54-56]. Briefly, ultrathin sections of lung tissue were incubated overnight in a wet chamber with primary antibodies (Table 1 ) in $0.1 \%$ BSAc (Aurion) in PBS containing 0.05\% Tween 20. On the next day, the sections on grids were washed 6 times on a series of $0.1 \%$ BSA-c (Aurion) in PBS containing $0.05 \%$ Tween 20 drops and then incubated for $120 \mathrm{~min}$ with ultrasmall immunogold goat anti-rabbit Fab fragments (Aurion) in 0.1\% BSA-c (Aurion), diluted with 1:400 in PBS containing 
$0.05 \%$ Tween 20 . Then, the grids with sections were rinsed shortly $(3 \times 3 \mathrm{~min})$ with $0.1 \%$ BSA in PBS containing $0.05 \%$ Tween 20 followed by the washing with PBS $(3 \times 3 \mathrm{~min})$. Thereafter, the antigen-antibody complexes were fixed for $10 \mathrm{~min}$ with $2 \%$ glutaraldehyde in PBS. The fixative was washed away with a drop series of PBS $(3 \times 3 \mathrm{~min})$, followed by $(6 \times 3 \mathrm{~min})$ aqua dest. Silver intensification was done according to the method of Danscher in a light tight box for $25 \mathrm{~min}$ at RT [57]. Thereafter, grids with sections were washed for 6 times ( $3 \mathrm{~min}$ each) with aqua dest. Sections were contrasted with uranyl acetate $(2 \mathrm{~min})$ and lead citrate (45s) and thereafter examined with a LEO 906 transmission electron microscope (LEO Electron Microscopy, Oberkochen, Germany) equipped with a $2 \mathrm{k}$-camera (TRS, Troendle systems).

2.4. Immunofluorescence on Paraffin-Embedded Tissue. The detailed protocol for perfusion fixation, paraffin embedding, sectioning of lung tissue, and subsequent immunofluorescence for newborn, P15, and adult lungs was described previously [55]. Briefly, perfusion-fixed lungs (4\% PFA in PBS, pH 7.4) were embedded into paraffin (Paraplast, Sigma-Aldrich, St. Louis, MO, USA) using an automated vacuum tissue processor (Leica TP 1020) and sections (2-3 $\mu \mathrm{m})$ were cut with Leica RM2135 rotation microtome and processed for double immunofluorescence. The dilutions of the primary and secondary antibodies used are listed in Table 1. Negative controls for secondary antibody reaction were processed in parallel by addition of PBST buffer instead of the first antibodies. Nuclei were visualized with $1 \mu \mathrm{M}$ TOTO-3 iodide (molecular probes) for $10 \mathrm{~min}$ at RT. Samples were analyzed by confocal laser scanning microscopy (CLSM) with a Leica TCS SP5 (Leica Mikrosysteme Vertrieb $\mathrm{GmbH}$, Wetzlar, Germany). All images were processed with Adobe Photoshop CS5.

2.5. Preparation of Whole Lung Homogenates for Protein Analysis (Western Blotting). For Western blotting, 3 lungs each from the newborn, P15, and adult mice were collected and stored at $-80^{\circ} \mathrm{C}$ prior to homogenization. The lung tissue of each group was cut into small pieces and homogenized in $2 \mathrm{ml}$ ice-cold homogenization buffer as previously described [55].

2.6. Western Blotting. For Western blot analysis, $50 \mu \mathrm{g}$ of lung homogenates from the newborn, P15, and adult mice was separated on $10 \%$ SDS-polyacrylamide gels using a Bio-Rad gel electrophoresis apparatus (Bio-Rad, München, Germany) as previously described [55]. Dilutions of primary antibodies used are listed in Table 1.

2.7. RNA Isolation. For RNA isolation, $100 \mathrm{mg}$ of frozen lung tissue was homogenized with an IKA T 25 ULTRA TURRAX (IKA, Germany) in $1 \mathrm{ml}$ RNAzol (RNAzol ${ }^{\circledR}$ RT, Sigma-Aldrich). Then, $0.4 \mathrm{ml}$ of RNase-free water per $\mathrm{ml}$ of RNazol was added and left for $15 \mathrm{~min}$ at RT. The lysate was centrifuged at $12,000 \mathrm{~g}$ for $15 \mathrm{~min}$ and the supernatant was transferred to a fresh tube to which an equal volume of $100 \%$ isopropanol was added. After that, the lysate was centrifuged at $12,000 \mathrm{~g}$ for $10 \mathrm{~min}$ and the supernatant was discarded. The RNA pellet was washed twice with $0.5 \mathrm{ml}$ of $75 \%$ ethanol per $\mathrm{ml}$ of supernatant. The RNA was centrifuged at $8000 \mathrm{~g}$ for $3 \mathrm{~min}$ at RT, and the ethanol was removed. Finally, the RNA pellet was solubilized in RNase-free water at concentration of $1-2 \mu \mathrm{g} / \mathrm{ml}$. The purity and quantification of RNA was determined with a spectrophotometer.

2.8. cDNA Synthesis. $1 \mu \mathrm{g}$ total RNA from adult, P15, and new born lungs was reverse transcribed to cDNA using $1 \mu \mathrm{l}$ of (dT) 12-18 primer (Invitrogen, Germany) and $1 \mu \mathrm{l}$ of SuperScript ${ }^{\mathrm{TM}}$ II Reverse Transcriptase (RT) Kit (Invitrogen, Germany) according to the manufacturer's protocol. The reaction was incubated in a Biometra Trio Thermocycler (The Netherlands). The qRT-PCR of target genes, described in Table 2, was performed in the iCycler $\mathrm{IQ}^{\mathrm{TM}}$ Real-Time PCR Detection System (Bio-Rad, USA). The reactions were set up with the $\mathrm{SYBR}^{\mathrm{TM}}$ Green PCR mix (Life Technologies) according to the manufacturer's protocol. The PCR cycle consisted of an initial cycle of $95^{\circ} \mathrm{C}$ for $3 \mathrm{~min}$ followed by 42 repeated cycles of $95^{\circ} \mathrm{C}$ for $15 \mathrm{~s}$, $60^{\circ} \mathrm{C}$ annealing temperature for $30 \mathrm{~s}$, and the primer extension at $72^{\circ} \mathrm{C}$ for $1 \mathrm{~min}$. The real-time PCR primer pairs used in this study are listed in Table 2 . All reactions were run in triplicates. Calculation of the relative gene expression was done by the $2^{-\mathrm{ddC}}$ method, where $\mathrm{dC}_{\mathrm{T}}=$ $\left(\mathrm{C}_{\mathrm{T}}\right.$ target gene $-\mathrm{C}_{\mathrm{T}}$ internal control gene) using $\mathrm{GAPDH}$ as an endogenous control.

2.9. Statistics. Data are expressed as mean \pm standard deviation. Differences between groups were evaluated by Student's unpaired $t$-test and one-way analysis of variance (ANOVA) using Tukey's test. Data were considered statistically significant if $p<0.05$.

\section{Results}

3.1. Abundance of Mitochondrial Proteins in Lung Homogenates. To characterize the differential abundance of mitochondrial encoded proteins, immunoblot analysis of distinct mitochondrial proteins in lung homogenates from newborn, P15, and adult animals was performed. The results revealed a significant and continuous increase in the abundance of polymerase gamma 2 (POLG2), ATP synthase (ATP5b), and cytochrome oxidase subunit II (COX2) from the newborn to adult lungs with high levels of abundance in adult lungs in comparison to the low levels of abundance in the lungs of newborn animals (Figures 1(a) and 1(b)). Similarly, cytochrome oxidase subunit I (COX1) also showed a continuous upregulation as was observed in P15 and adult lungs in comparison to the newborn lungs. However, the protein abundance of COX1 detected in the newborn was higher than the ones for COX2 as well as ATP synthase and POLG2. Interestingly, the expression of NADP dehydrogenase complex I subunit I (MT-ND1) was only present in very low amounts in the lungs of newborns but increased thereafter to a still relatively low level in adults. The succinate dehydrogenase complex II subunit D (SDHD) was differently altered. It exhibited a higher abundance level in the newborn 
TABLE 2: List of primers used in this study for qRT-PCR (the annealing temp was $60^{\circ} \mathrm{C}$ ).

\begin{tabular}{|c|c|c|c|c|}
\hline Full name & $\begin{array}{l}\text { Gene } \\
\text { target }\end{array}$ & $\begin{array}{l}\text { Sense primer }\left(5^{\prime}-3^{\prime}\right) \\
20-23 \text { mers } \\
\end{array}$ & $\begin{array}{l}\text { Antisense primer }\left(5^{\prime}-3^{\prime}\right) \\
20-24 \text { mers } \\
\end{array}$ & $\begin{array}{c}\text { Size of } \\
\text { product }\end{array}$ \\
\hline $\begin{array}{l}\text { Mitochondrially encoded NADH:ubiquinone } \\
\text { oxidoreductase core subunit } 1\end{array}$ & $m t-N d 1$ & $\begin{array}{l}\text { GCTTTACGAGCCGTAG } \\
\text { CCCA }\end{array}$ & $\begin{array}{c}\text { GGGTCAGGCTGGCAGA } \\
\text { AGTAA }\end{array}$ & 147 \\
\hline $\begin{array}{l}\text { Mitochondrially encoded NADH:ubiquinone } \\
\text { oxidoreductase core subunit } 2\end{array}$ & $m t-N d 2$ & $\begin{array}{c}\text { CCTCCTGGCCATCGTA } \\
\text { CTCA }\end{array}$ & $\begin{array}{l}\text { GAATGGGGCGAGGCCT } \\
\text { AGTT }\end{array}$ & 124 \\
\hline $\begin{array}{l}\text { Mitochondrially encoded NADH:ubiquinone } \\
\text { oxidoreductase core subunit } 3\end{array}$ & $m t-N d 3$ & $\begin{array}{l}\text { TAGTTGCATTCTGACT } \\
\text { CCCCCA }\end{array}$ & $\begin{array}{l}\text { GAGAATGGTAGACGTG } \\
\text { CAGAGC }\end{array}$ & 100 \\
\hline $\begin{array}{l}\text { Mitochondrially encoded NADH:ubiquinone } \\
\text { oxidoreductase core subunit } 4\end{array}$ & $m t-N d 4$ & $\begin{array}{c}\text { CGCCTACTCCTCAGTT } \\
\text { AGCCA }\end{array}$ & $\begin{array}{l}\text { TGATGTGAGGCCATGT } \\
\text { GCGA }\end{array}$ & 112 \\
\hline $\begin{array}{l}\text { Mitochondrially encoded NADH:ubiquinone } \\
\text { oxidoreductase core subunit } 4 \mathrm{~L}\end{array}$ & $m t-N d 4 l$ & $\begin{array}{l}\text { AGCTCCATACCAATCC } \\
\text { CCATCAC }\end{array}$ & $\begin{array}{l}\text { GGACGTAATCTGTTCC } \\
\text { GTACGTGT }\end{array}$ & 109 \\
\hline $\begin{array}{l}\text { Mitochondrially encoded NADH:ubiquinone } \\
\text { oxidoreductase core subunit } 5\end{array}$ & $m t-N d 5$ & $\begin{array}{l}\text { GGCCCTACACCAGTTT } \\
\text { CAGC }\end{array}$ & $\begin{array}{c}\text { AGGGCTCCGAGGCAAA } \\
\text { GTAT }\end{array}$ & 134 \\
\hline $\begin{array}{l}\text { Mitochondrially encoded NADH:ubiquinone } \\
\text { oxidoreductase core subunit } 6\end{array}$ & $m t-N d 6$ & $\begin{array}{c}\text { CTTGATGGTTTGGGAG } \\
\text { ATTGG }\end{array}$ & $\begin{array}{l}\text { ACCCGCAAACAAAGAT } \\
\text { CACC }\end{array}$ & 138 \\
\hline Succinate dehydrogenase complex subunit D & Sdhd & $\begin{array}{c}\text { GCTCGAGCTCTCCTAC } \\
\text { TCC }\end{array}$ & $\begin{array}{c}\text { GCTTGGTGACAGGTGA } \\
\text { ATGT }\end{array}$ & 117 \\
\hline Mitochondrially encoded cytochrome b & $m t-C y t b$ & $\begin{array}{c}\text { TCCTTCATGTCGGACG } \\
\text { AGGC }\end{array}$ & $\begin{array}{l}\text { AATGCTGTGGCTATGA } \\
\text { CTGCG }\end{array}$ & 100 \\
\hline Mitochondrially encoded cytochrome c oxidase I & $\begin{array}{l}m t-\operatorname{Col} 1 \\
\operatorname{Cox} 1\end{array}$ & $\begin{array}{c}\text { TCAACATGAAACCCCC } \\
\text { AGCCA }\end{array}$ & $\begin{array}{c}\text { GCGGCTAGCACTGGTA } \\
\text { GTGA }\end{array}$ & 100 \\
\hline Mitochondrially encoded cytochrome c oxidase II & $\begin{array}{l}m t-\mathrm{Co} 2 \\
\operatorname{Cox} 2\end{array}$ & $\begin{array}{c}\text { ACCTGGTGAACTACGA } \\
\text { CTGCT }\end{array}$ & $\begin{array}{c}\text { TCCTAGGGAGGGGACT } \\
\text { GCTC }\end{array}$ & 121 \\
\hline Mitochondrially encoded cytochrome c oxidase III & $\begin{array}{l}m t-C o 3 \\
\text { Cox3 }\end{array}$ & $\begin{array}{c}\text { CCAAGGCCACCACACT } \\
\text { CCTA }\end{array}$ & $\begin{array}{c}\text { GGTCAGCAGCCTCCTA } \\
\text { GATCA }\end{array}$ & 150 \\
\hline Mitochondrially encoded ATP synthase 6 & $m t-A t p 6$ & $\begin{array}{c}\text { AGCTCACTTGCCCACT } \\
\text { TCCT }\end{array}$ & $\begin{array}{c}\text { AAGCCGGACTGCTAAT } \\
\text { GCCA }\end{array}$ & 114 \\
\hline Mitochondrially encoded $12 \mathrm{~S}$ RNA & $m t-R n r 1$ & $\begin{array}{c}\text { ACACCTTGCCTAGCCA } \\
\text { CACC }\end{array}$ & $\begin{array}{c}\text { GTGGCTGGCACGAAAT } \\
\text { TTACCA }\end{array}$ & 112 \\
\hline Mitochondrially encoded 16S RNA & $m t-R n r 2$ & $\begin{array}{c}\text { ACACCGGAATGCCTAA } \\
\text { AGGA }\end{array}$ & $\begin{array}{c}\text { ATACCGCGGCCGTTAA } \\
\text { ACTT }\end{array}$ & 148 \\
\hline Transcription factor B1, mitochondrial & $T f b 1 m$ & $\begin{array}{c}\text { GGCTGAGAGACTTGTA } \\
\text { GCCACT }\end{array}$ & $\begin{array}{c}\text { AGGTGCACCACTCCTA } \\
\text { CATCAA }\end{array}$ & 150 \\
\hline Transcription factor B2, mitochondrial & $T f b 2 m$ & $\begin{array}{c}\text { TTTGGCAAGTGGCCTG } \\
\text { TGAC }\end{array}$ & $\begin{array}{c}\text { ACTGATTCCCCGTGCT } \\
\text { TTGACT }\end{array}$ & 109 \\
\hline Mitochondrial transcription factor A & Tfam & $\begin{array}{c}\text { GCCCGGCAGAGACG } \\
\text { GTTAAA }\end{array}$ & $\begin{array}{c}\text { GCCGAATCATCCTTTG } \\
\text { CCTCC }\end{array}$ & 137 \\
\hline Polymerase (RNA) mitochondrial & Polrmt & $\begin{array}{c}\text { ACAACACCGTGATGCT } \\
\text { TGGC }\end{array}$ & $\begin{array}{c}\text { GAACATCCTGGTCCCT } \\
\text { GCGT }\end{array}$ & 150 \\
\hline Polymerase (DNA) gamma 2, accessory subunit & Polg2 & $\begin{array}{c}\text { CTGGTTGCGTCATCGG } \\
\text { CTTC }\end{array}$ & $\begin{array}{c}\text { TGCTTCCCTTGCGTCC } \\
\text { CAAT }\end{array}$ & 101 \\
\hline Glyceraldehyde 3-phosphate dehydrogenase & GAPDH & $\begin{array}{c}\text { TGGCAAAGTGGAGATT } \\
\text { GTTGCC }\end{array}$ & $\begin{array}{c}\text { AAGATGGTGATGGGCT } \\
\text { TCCCG }\end{array}$ & 156 \\
\hline
\end{tabular}

in comparison to all other mitochondrial proteins. Similar to other mitochondrial proteins, it was upregulated at P15 lungs but decreased thereafter to an intermediate level in adult animals (Figures 1(a) and 1(b)). The reason for not presenting blots for complex III is that the antibody did not work in Western blots, whereas it worked perfectly well in morphology for immunogold labelling (Figures 2(d)-2(f)), suggesting that this antibody mainly detected the native (nondenatured) protein.
3.2. Relative mRNA Expression of Different Complex I Gene Subunits during Postnatal (Newborn, P15, and Adult) Development of the Mouse Lung. To ascertain the expression of genes encoding mitochondrial proteins during postnatal development, total RNA was isolated from 3 lung tissue samples of newborn, P15, and adult mice and subsequently analysed by quantitative polymerase chain reaction (qRT-PCR). These results revealed a continuous and significant increase in the expression of all complex I genes 

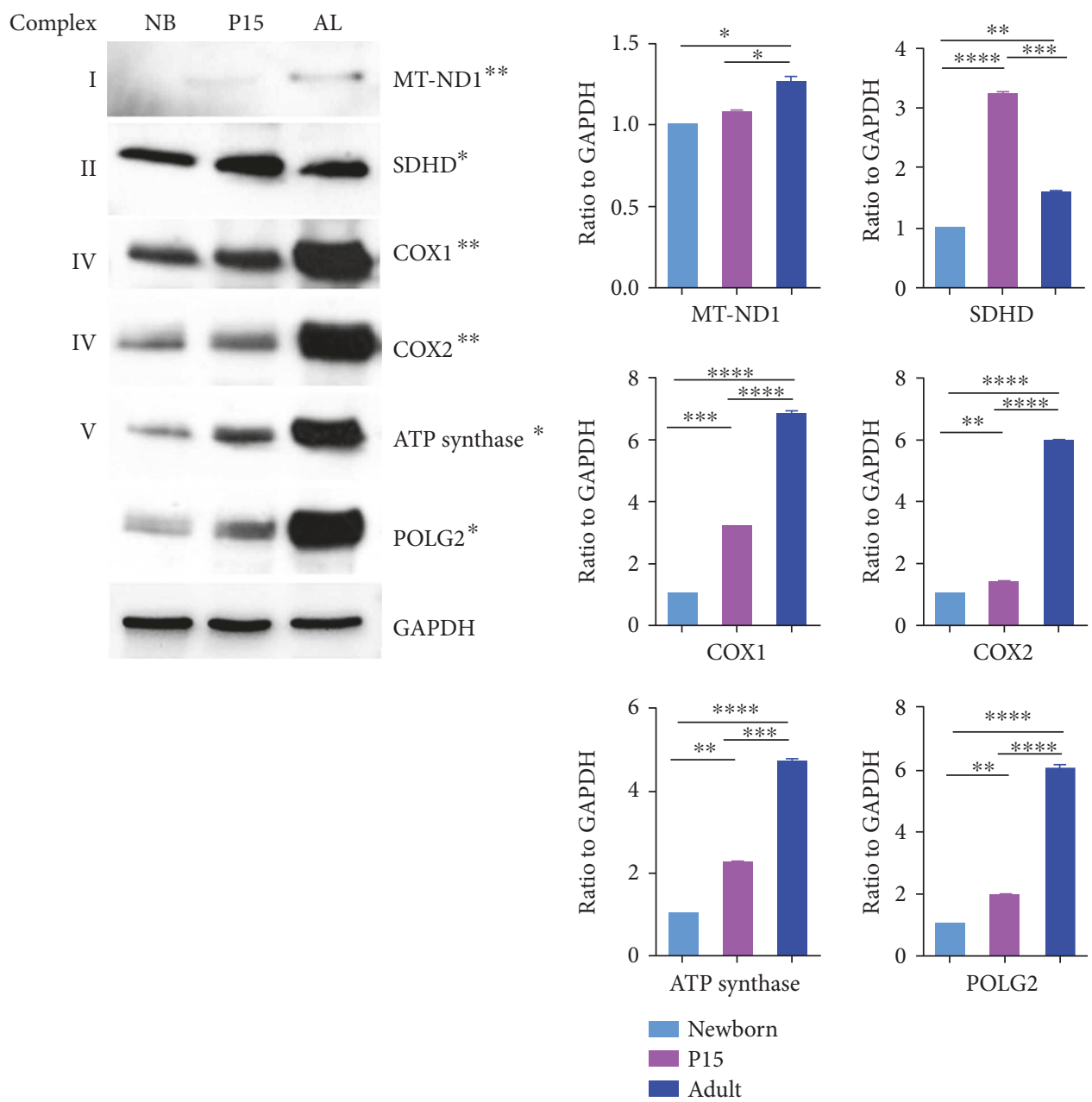

(a)

(b)

FIGURE 1: Western blot analyses of distinct mitochondrial proteins in lung homogenates from newborn, P15, and adult mice. (a) Following the homogenization, $50 \mu \mathrm{g}$ of protein isolated from the lungs of each group (NB, P15, and adult) was resolved by $10 \%$ SDS-polyacrylamide gel electrophoresis, and the blots were immunostained with anti-MT-ND1, anti-SDHD, anti-COX1 (OXPHOS complex IV subunit I), anti-COX2 (OXPHOS complex IV subunit II), anti-ATP synthase (ATP5b), and anti-POLG2. GAPDH was used as a loading control. * Nuclear-encoded protein. ${ }^{* *}$ Mitochondrially encoded protein. (b) Bar graphs summarizing normalized data. $p$ values were calculated by the one-way ANOVA using Tukey's test. $n=3 ;{ }^{*} p \leq 0.05,{ }^{* *} p \leq 0.01,{ }^{* * *} p \leq 0.001$, and ${ }^{* * * *} p \leq 0.0001$.

$(m t-N d 1, m t-N d 2, m t-N d 3, m t-N d 4, m t-N d 4 l, m t N d 5$, and $m t-N d 6$ ) (Figures 3(a)-3(g)). This mRNA upregulation was observed in the lungs from both P15 and adult animals in comparison to the lungs from the newborn mice. Similarly, the mRNA expression of these genes showed a significant elevation in the lungs from adult animals in comparison to the lungs from the P15 mice. Interestingly, the $m t-N d 5$ (Figure 3(f)) showed the highest expression among the other complex I subunits, where an increase of 2.5 and 6 times was observed in the lungs from P15 and adult animals, respectively, as compared to the neonates. The second highest increase in the gene expression was detected for $m t-N d 3$ (Figure 3(c)), $m t-N d 4 l$ (Figure 3(e)), and $m t-N d 6$ (Figure $3(\mathrm{~g})$ ) genes where a 2 and 4 times increase in the mRNA levels was observed in the lungs of the 15-day and 12-week animals, respectively. The real-time PCR results showed that $m t-N d 2$ and $m t-N d 4$ (Figures 3(b) and 3(d)) genes were much less upregulated (by approximately 2 and 2.8 times) in P15 and adult lungs, respectively, in comparison to $m t-N d 3, m t-N d 4 l$, and $m t N d 5$ (Figures 3(c), 3(e), and 3(f)). The expression of complex I subunit 1 gene $m t-N d 1$ (Figure $3(\mathrm{a})$ ) was the lowest among the other complex I subunits by only showing an increase of by 1.5 and 2 times in the P15 and adult animals, respectively, in comparison to the newborns.

\subsection{Relative Gene Expression Levels for Complex II-V mRNAs} during Different Stages of the Postnatal Mouse Lung Development. Real-time PCR results of the total lung RNA content revealed a continuous increase in the expression of the mRNA for the nuclear-encoded succinate dehydrogenase subunit D (Sdhd) (Figure 4(a)), mitochondrially encoded cytochrome b (mt-Cytb) (Figure 4(b)), mitochondrially encoded cytochrome $c$ oxidase subunits I and II ( $m t-\mathrm{Co} 1$ and $m t$-Co2) (Figures $4(\mathrm{c})$ and $4(\mathrm{~d})$ ), and mitochondrially encoded ATP synthase 6 (mt-Atp6) (Figure 4(f)) from 


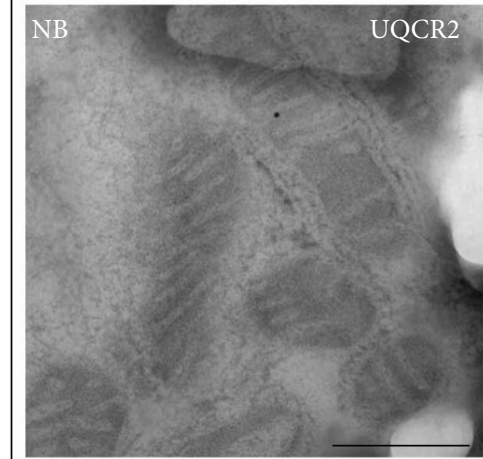

(a)

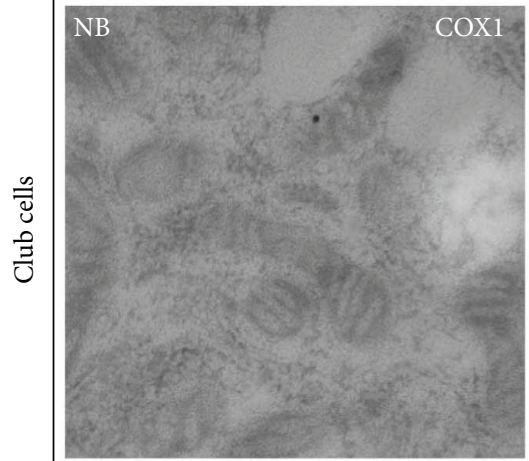

(d)

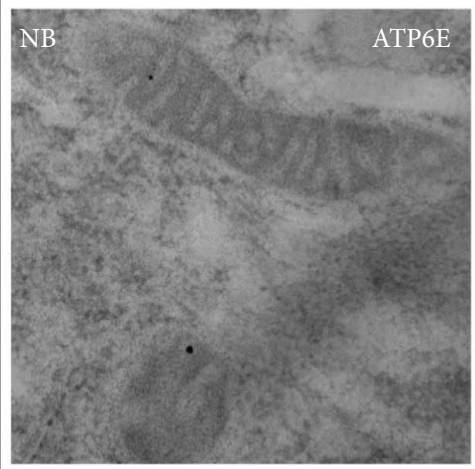

(g)

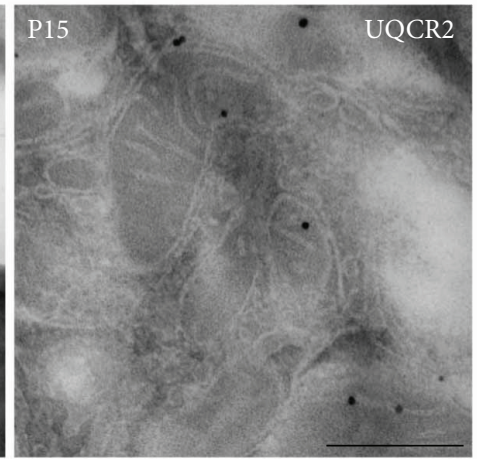

(b)

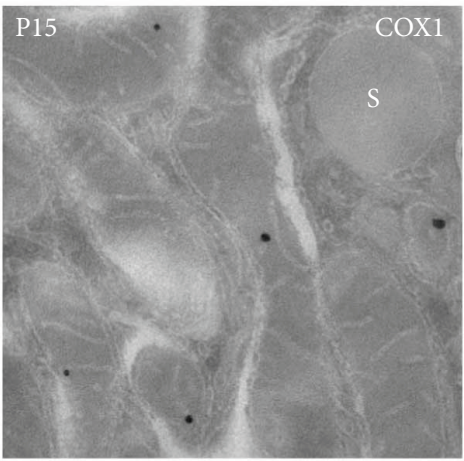

(e)

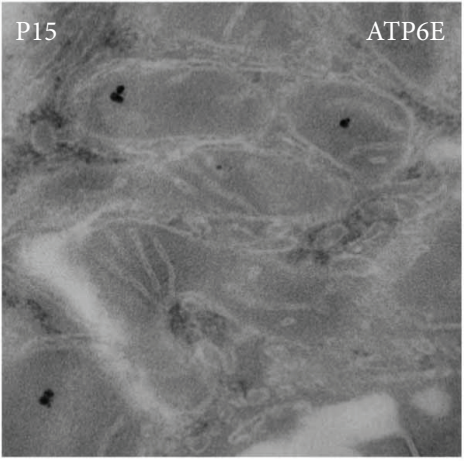

(h)

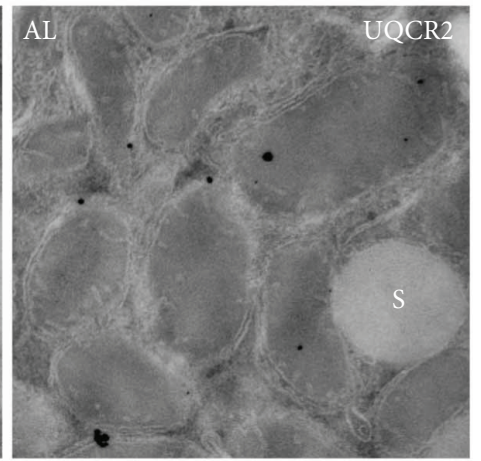

(c)

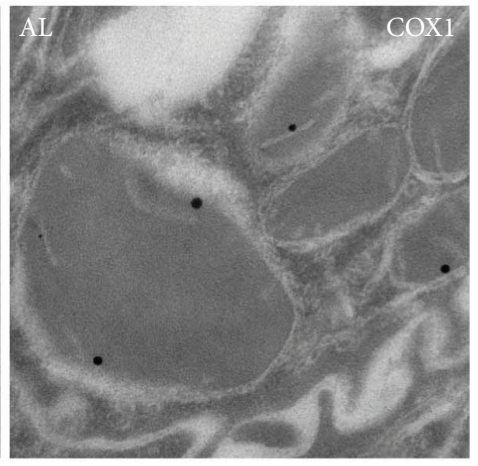

(f)

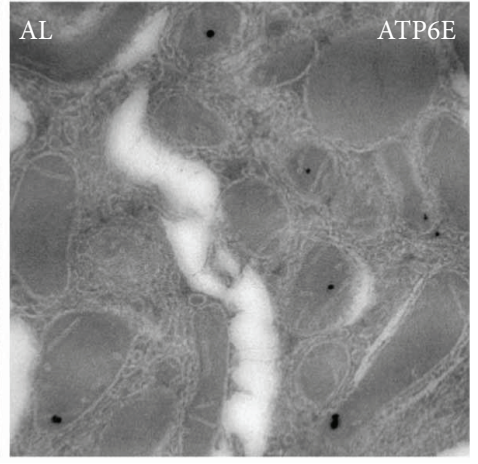

(i)

FIGURE 2: Electron micrographs showing immunogold labelling for mitochondrial proteins in ultrathin sections of club cells in newborn (NB), P15, and adult (AL) animals. Lung tissue processed for immunoelectron microscopy was incubated with gold-labelled secondary antibody particles and thereafter contrasted with uranyl acetate and lead citrate prior to analysis by transmission electron microscopy. (a-i) Immunogold labelling in mitochondria of club cells for (a-c) complex III (UQCR2), (d, e) complex IV (COX1), and $(\mathrm{g}, \mathrm{h}$ ) complex V (ATP6E). $S$, secretory granule. Bars: $\mathrm{a}, \mathrm{c}, \mathrm{e}, \mathrm{g}$, and $\mathrm{i}=0.5 \mu \mathrm{m}$ and $\mathrm{b}$, d, f, and $\mathrm{h}=0.25 \mu \mathrm{m}$.

newborn to adult stage. Complex II Sdhd (Figure 4(a)) exhibited the lowest but still significant increase of gene expression among all mRNAs for respiratory complexes. The mRNA expression level for complex III ( $m t-C y t b)$ (Figure 4(b)) was strongly upregulated (4 times) in the lungs of adults in comparison to the lungs of the newborns. Interestingly, the expression of the mRNAs for the three mitochondrially encoded complex IV subunits were altered differently. The $m t$-Co2 (Figure 4(d)) was the most highly expressed among the other 2 subunits since it already increased 3 times in the lungs from P15 animals and up to 4 times in the adult lungs in comparison to the situation in the lung samples from the newborns. The mRNA level for $m t-C o 1$ (Figure $4(\mathrm{c})$ ) was only increased by 1.5 and 2.5 times in P15 and adult animals, respectively, and these expression levels were the lowest compared to the ones for complex III subunits II ( $m t$-Co2) and III (mt-Co3). When compared to the mRNAs for respiratory complex III subunits, the mRNA level of $m t-C o 3$ is not induced significantly between the values of P15 and adult animals. The mRNA levels for $m t$-Atp6 (Figure 4(f)) exhibited a 1.5 and 2.5 times elevation in the lungs from P15 and adult mice in comparison to newborn animals.

3.4. Expression of mtDNA Transcription Machinery, Mitochondrially Encoded RNAs, and Mitochondrial DNA Polymerase Genes. Real-time PCR results revealed that the 


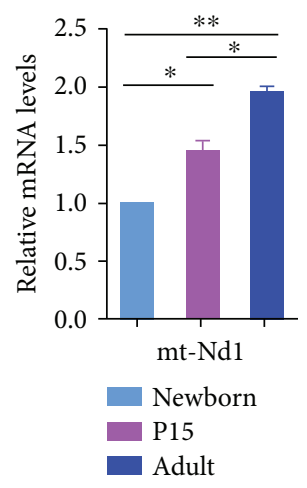

(a)

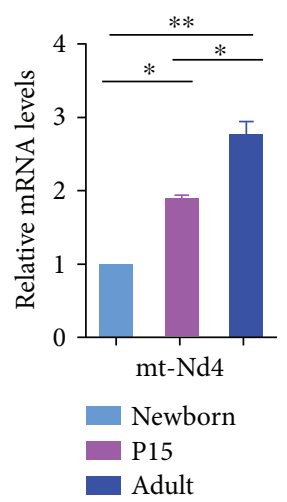

(d)

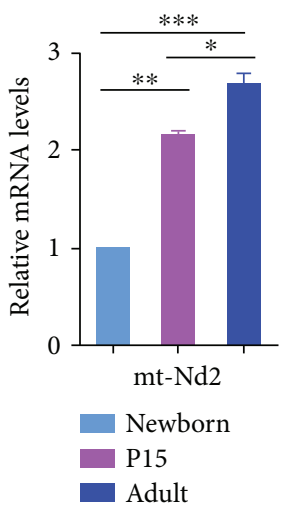

(b)

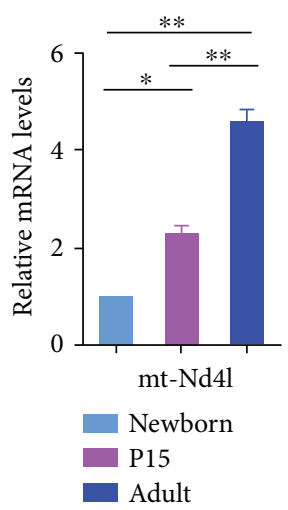

(e)

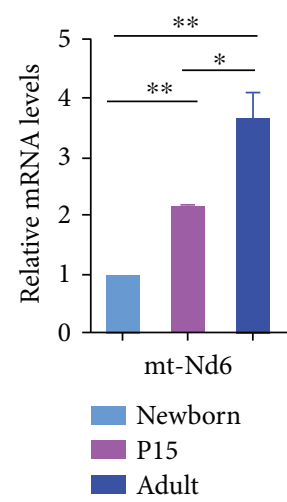

(g)

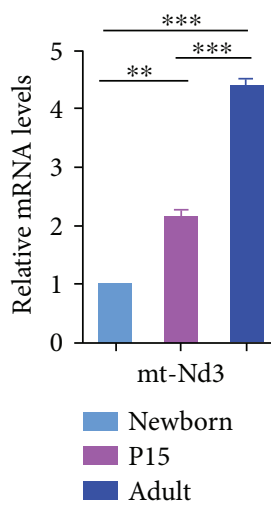

(c)

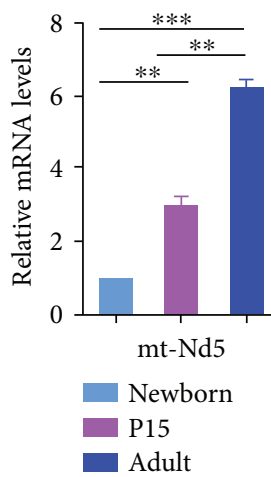

(f)

FiguRE 3: mRNA expression of the mitochondrially encoded complex I genes in the new born, P15, and adult lung tissues as determined via quantitative real-time PCR (qRT-PCR) analysis. Total RNA was extracted from the lung tissues of newborn (NB), P15, and adult (AL) mice using RNAzol, reverse transcribed and subjected to qRT-PCR using specific primers for the mRNAs for distinct subunits of the mitochondrially encoded complex I ( $m t-N d 1, m t-N d 2, m t-N d 3, m t-N d 4, m t-N d 4 l, m t-N d 5$, and $m t-N d 6)$. The bar graphs represent relative levels of the transcripts in three independent experiments. $p$ values were calculated by the one-way ANOVA using Tukey's test. Statistical significance is indicated by ${ }^{*} p<0.05,{ }^{* *} p<0.01$, and ${ }^{* * *} p<0.001$. The mRNA levels were normalized to the ones of GAPDH.

rRNA expression patterns of genes encoding mitochondrial RNA were distinct from each other. A 1.4 and 2.4 times increase in the $m t-R n r 1$ (Figure 5(a)) expression was observed in the lungs from P15 and adult mice, respectively. The second mitochondrial encoded rRNA, $m t-R n r 2$ (Figure 5(b)), only showed a 1.4 times increase in the lungs of adult animals in comparison to the lungs of newborn mice whereas no significant change in the rRNA expression of this gene was observed in the P15 lungs in comparison to the newborn and adult animals. Tfb1m and Tfam (Figures 5(c) and $5(\mathrm{e})$ ), the genes encoding transcription factors implicated in the mitochondrial DNA (mtDNA) transcription machinery, were regulated in a similar pattern with 1.7 times higher expression levels in the lungs of P15 and adult animals when compared to the newborn mice. No significant changes in the expression levels of these genes were observed between 


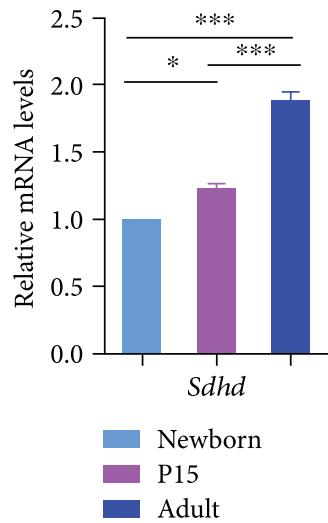

(a)

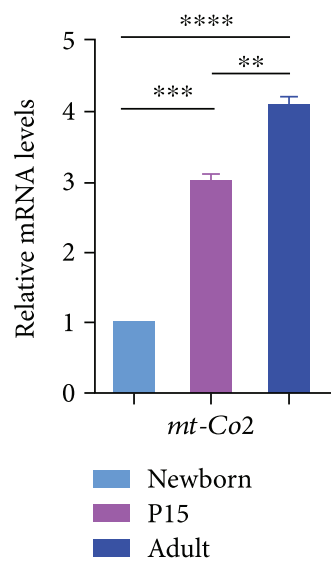

(d)

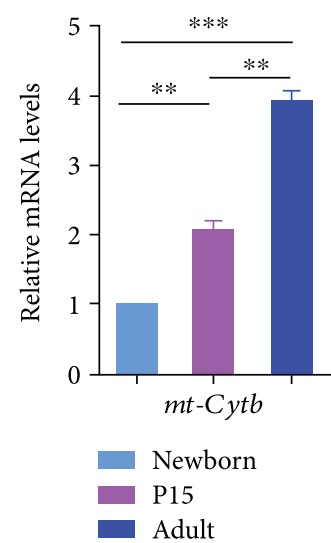

(b)

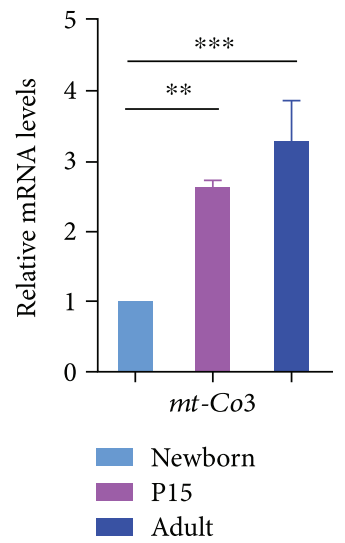

(e)

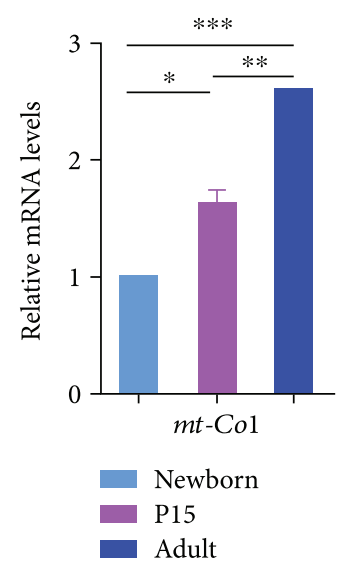

(c)

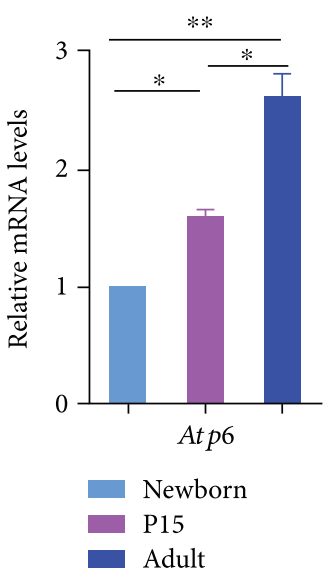

(f)

FIGURE 4: mRNA expression of the complex II-V genes in new born, P15, and adult lung tissues as determined by real-time PCR analyses. Total RNA was extracted from lung tissue of newborn (NB), P15, and adult (AL) mice using RNAzol, reverse transcribed and subjected to qRT-PCR using specific primers for mRNAs of (a) the nuclear-encoded succinate dehydrogenase complex II subunit D $(S d h d)$, (b) the mitochondrially encoded complex III ( $m t-C y t b)$, (c-e) the different complex IV subunits ( $m t$-Co1, $m t$-Co2, and $m t$ Co3), and (f) the mitochondrially encoded complex V (mt-Atp6). The bar graphs represent relative levels of the transcripts in three independent experiments. $p$ values were calculated by the one-way ANOVA using Tukey's test. Statistical significance is indicated by ${ }^{*} p<0.05,{ }^{* *} p<0.01,{ }^{* * *} p<0.001$, and ${ }^{* * * *} p<0.0001$. The mRNA levels were normalized to the ones of GAPDH.

the P15 and adult stages. However, the mRNAs for Tfb $2 m$ and Polrmt (Figures 5(d) and 5(f)), which encode proteins involved in the mtDNA transcription machinery, showed a significant continuous postnatal elevation in the mRNA expression. The expression of mitochondrial DNA polymerase Polg2 (Figure 5(g)) was differentially altered, exhibiting only a significant 2-time elevation in the mRNA levels in the adult lungs in comparison to the ones of newborn and P15 stages.

3.5. Imaging of Mitochondrial Structural Alterations by Transmission Electron Microscopy (TEM). To visualize the mitochondrial ultrastructure in the uranyl acetate and lead citrate, contrasted ultrathin lung tissue sections from newborn, P15, and adult mice transmission electron microscopy (TEM) were applied. The lung tissue from the newborn (NB), P15, and adult (AL) animals exhibited normal ultrastructure revealing alterations in the organization of mitochondria in the ciliated cells (left panel), club cells (middle panel), and alveolar epithelial type II (AECII) cells (right panel) in different stages of postnatal development. The micrographs of the ciliated cells (left panel) from the newborns (Figures 6(a) and 6(b)) show many mitochondria with lamellar cristae in the apical part of the cell directly underneath of the basal bodies to which cilia are attached. Additionally, the pools of glycogen were observed in the cytoplasm of the ciliated cells from the newborns. Starting from P15, the mitochondria changed to larger and elongated structures with more prominent cristae and a decline in the glycogen content was well observed postnatally.

Figure 6 (middle panel) reveals the typical organelle distribution in the club cells. The micrographs of the club cells from the newborns (Figures $6(\mathrm{~g})$ and $6(\mathrm{~h})$ ) revealed elongated mitochondria possessing lamellar cristae. Besides the mitochondria, a substantial part of the cytoplasm in club cells of newborn animals was filled with glycogen deposits. Almost no evidence of secretory activity was detected in the club cells of the newborns, whereas secretory granules were present in P15 (Figures 6(i) and 6(j)) animals. These data show distinct cell-autonomous ultrastructural changes in 


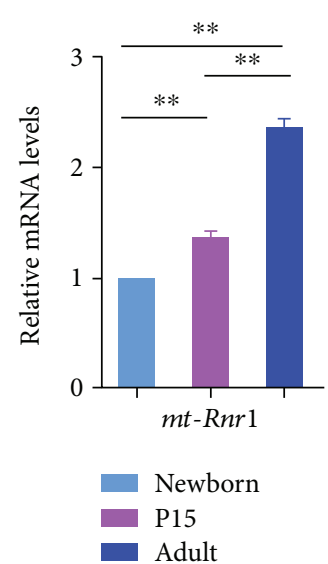

(a)

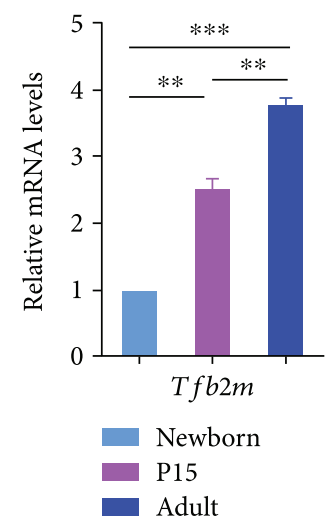

(d)

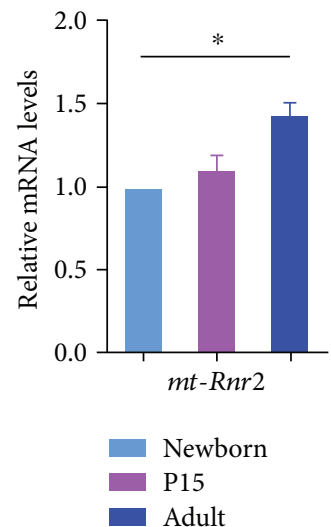

(b)

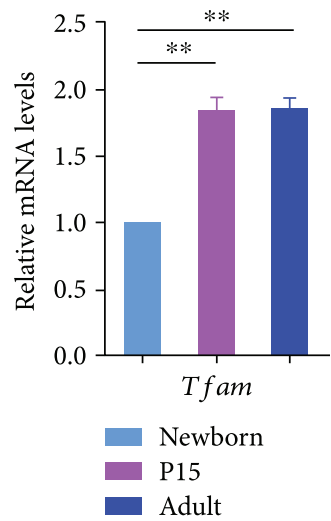

(e)

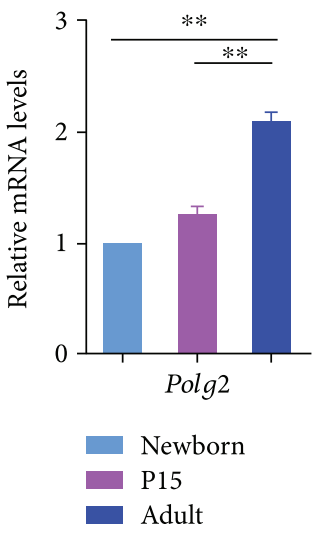

(g)

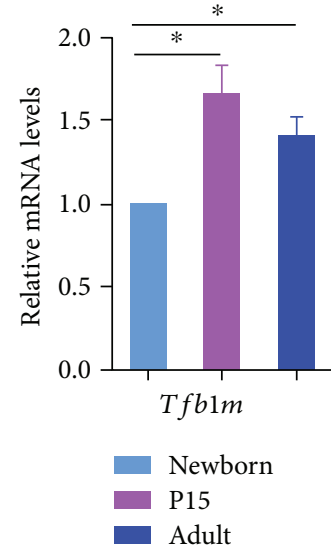

(c)

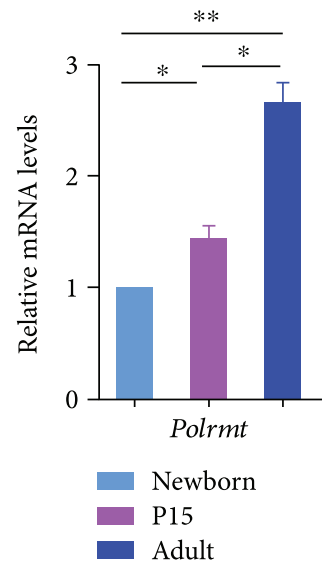

(f)

FIGURE 5: mRNA expression of the mtDNA transcription machinery genes, mitochondrially encoded RNA, and mitochondrial DNA polymerase in the new born, P15, and adult lung tissues as determined via quantitative real-time (qRT-PCR) analysis. Total RNA was extracted from the lung tissues of newborn (NB), P15, and adult (AL) mice using RNAzol, reverse transcribed and subjected to qRT-PCR using specific primers of the mtDNA transcription machinery (Polrmt, Tfam, $T f b 1 m$, and Tfb2m), mitochondrially encoded RNAs ( $m t-R n r 1$ and $m t-R n r 2)$, and mitochondrial DNA polymerase (Polg2) involved in mitochondrial DNA replication. The bar graphs represent relative levels of the transcripts in three independent experiments. Statistical significance is indicated by ${ }^{*} p<0.05,{ }^{* *} p<0.01$, and ${ }^{* * *} p<0.001$. The mRNA levels were normalized to the ones of GAPDH.

the club cells of newborn (Figures 6(g) and 6(h)) and P15 (Figures 6(i) and 6(j)) animals. The mitochondria in these cells were more numerous but contained fewer cristae. Moreover, the cytoplasmic glycogen - although still present in high amounts-appeared to be reduced. Electron-dense secretory granules (S) were clearly observed in the club cells of P15 animals suggesting secretory activity. The micrographs of the club cells in adult animals (Figures $6(\mathrm{k})$ and 6(l)) 


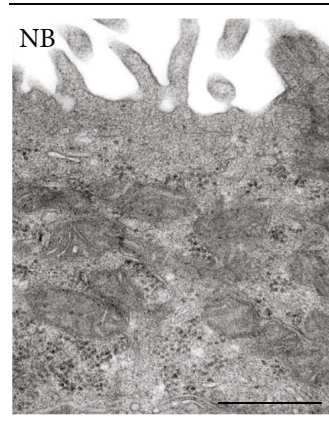

(a)

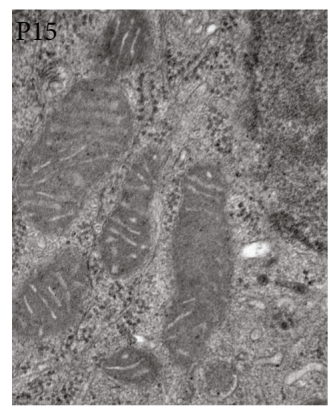

(c)

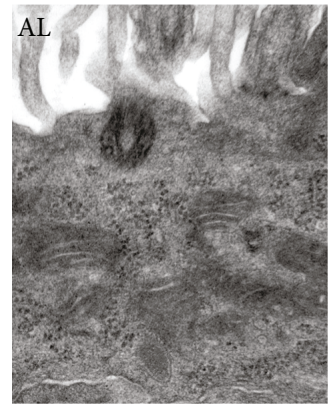

(e)

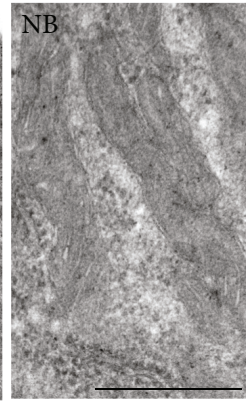

(b)

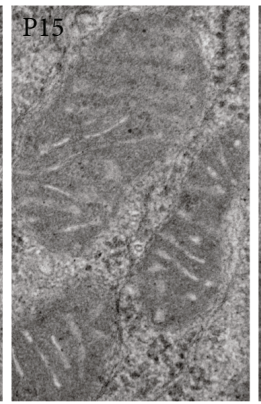

(d)

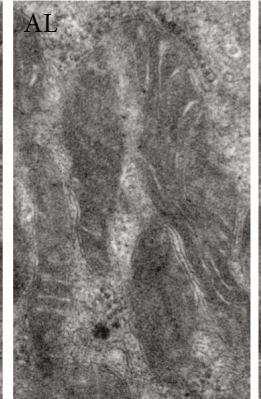

(f)

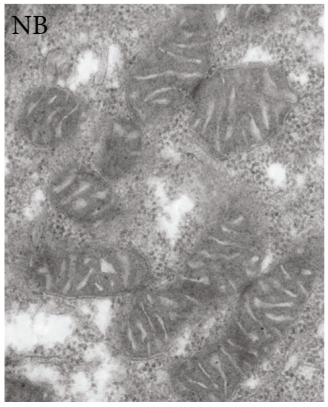

(g)

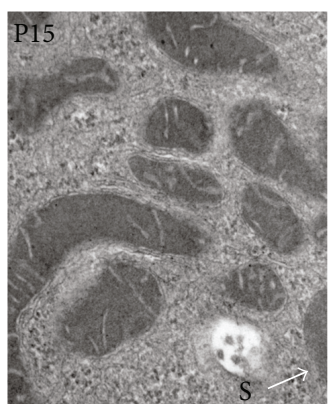

(i)

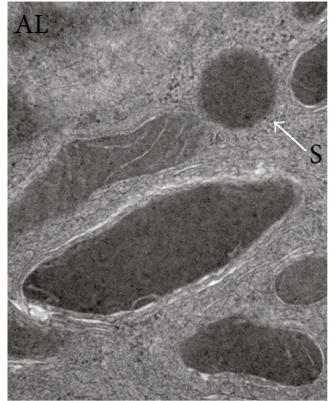

(k)

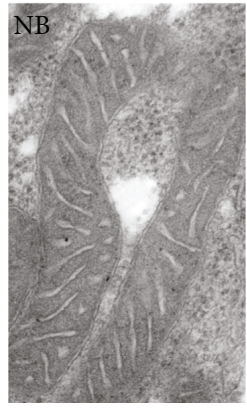

(h)

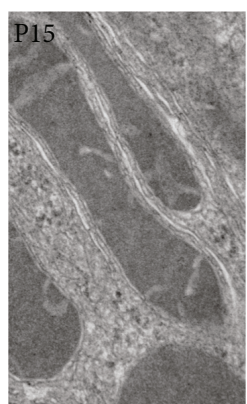

(j)

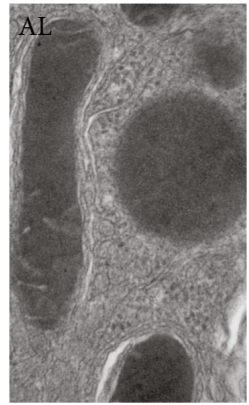

(1)

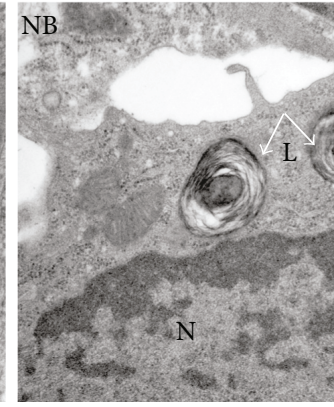

(m)

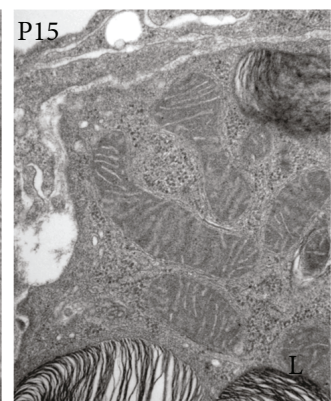

(o)

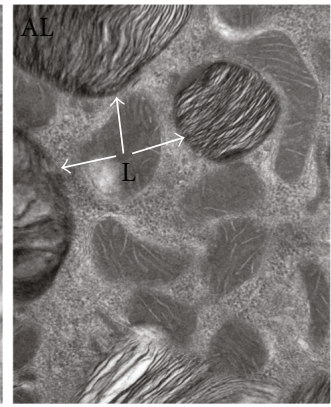

(q)

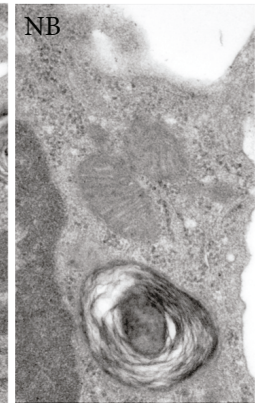

(n)

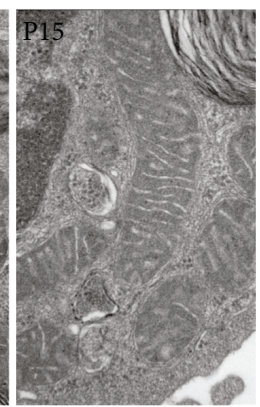

(p)

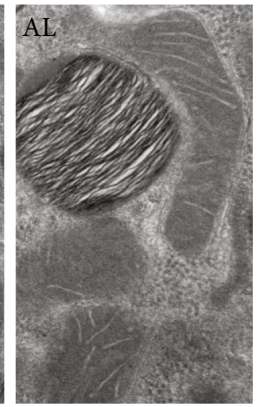

(r)

FIgURE 6: Transmission electron micrographs of mitochondrial ultrastructure in the ciliated cells, club cells, and alveolar epithelial type II cells (AECII) from the lungs of newborn (NB), P15, and adult (AL) animals. Ultrathin sections of lung samples for routine electron microscopy were contrasted with uranyl acetate and lead citrate prior to analysis by transmission electron microscopy. The left panel (a-f) represents the TEM images of ciliated cells, the middle panel ( $\mathrm{g}-\mathrm{l}$ ) represents the club cells, and the right panel ( $\mathrm{m}-\mathrm{r}$ ) represents the AECII cells. Higher magnifications of selected areas ( $b, d, f, h, j, l, n, p$, and $r)$. L, lamellar body; N, nucleus; $S$, secretory granule. Bars: $a, c, e, g, i, k, m$, $\mathrm{o}$, and $\mathrm{q}=0.5 \mu \mathrm{m}$ and $\mathrm{b}, \mathrm{d}, \mathrm{f}, \mathrm{h}, \mathrm{j}, \mathrm{l}, \mathrm{n}, \mathrm{p}$, and $\mathrm{r}=0.25 \mu \mathrm{m}$.

revealed large and elongated mitochondria in the clubformed apex which were almost devoid of cristae. Moreover, these micrographs demonstrated an increase in the abundance of secretory granules and a strong decrease in the proportion of cytoplasmic glycogen in the adult club cells in comparison to the 2 previously mentioned postnatal stages.

The micrographs of the right panel depict typical ultrastructure of the alveolar epithelial type II cells (AECII). Similar to the ultrastructure of club cells, AECII of the newborn animals (Figures 6(m) and 6(n)) showed an abundant glycogen content in their cytoplasm. The mitochondria, during this stage of postnatal development, appeared as single, spherical structures. Moreover, only few whirl-shaped lamellar bodies were detected in the cytoplasm of AECII at this stage. Starting from P15 (Figures 6(o) and 6(p)), the mitochondria changed in shape into a more elongated and branched structures with a more complex lamellar cristae as was also seen in adult animals (Figures 6(q) and $6(\mathrm{r}))$. In addition to this, alveolar epithelial type II cells of P15 to adult animals showed a gradual decline in the cytoplasmic glycogen amount. Despite a decline in glycogen content, the lamellar body number, size, and mature appearance with parallel lamellae gradually increased up to the adult stage.

3.6. Immunofluorescence Staining for Complex IV Subunits I and II. Immunofluorescence preparations of lung tissue 


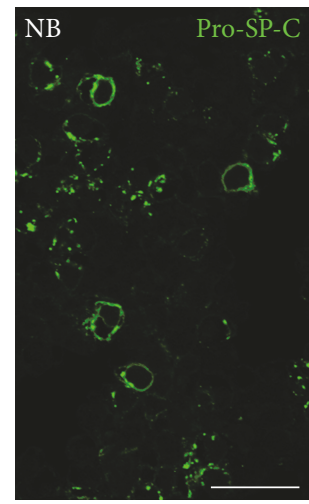

(a)

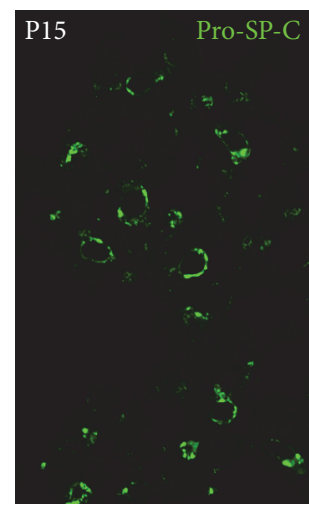

(d)

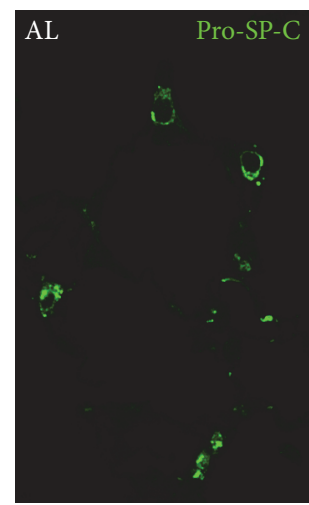

(g)

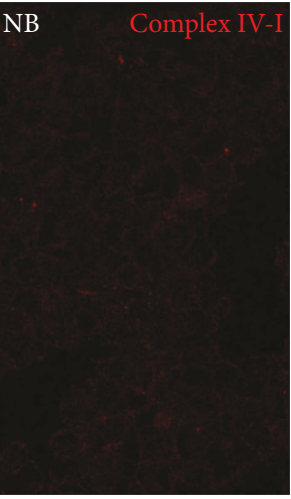

(b)

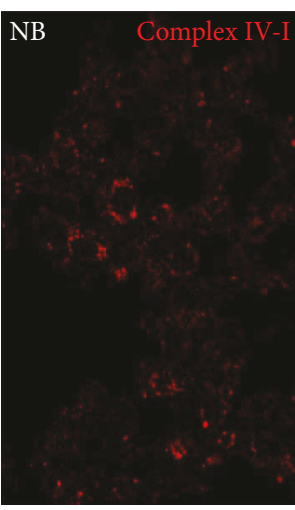

(e)

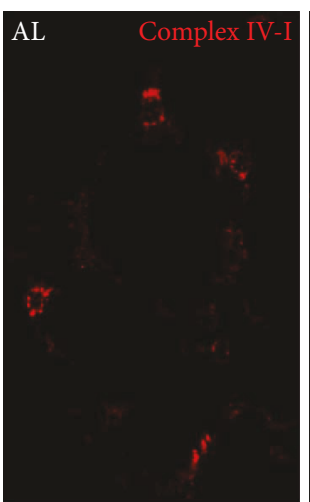

(h)

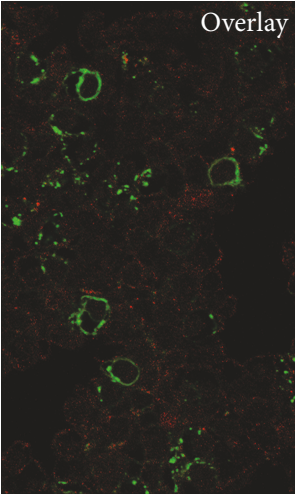

(c)

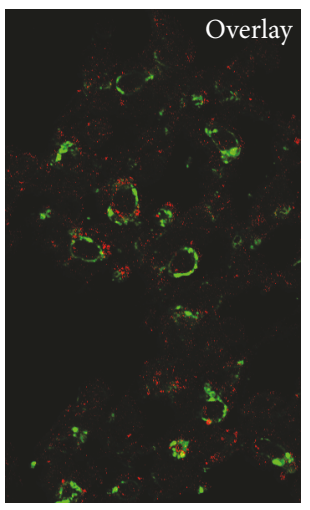

(f)

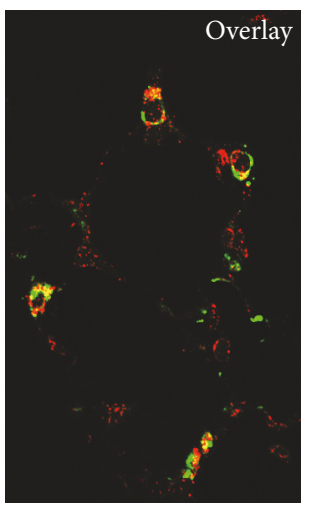

(i)

FIgURE 7: Representative immunofluorescence analysis of mitochondrial complex IV subunit I protein in AECII from lung tissue sections of newborn (NB), P15, and adult (AL) animals. Lung tissue samples from the three postnatal stages were embedded into paraffin. Thereafter, $3 \mu \mathrm{m}$ paraffin sections were cut with a rotation microtome and processed further for indirect double immunofluorescence. The lung sections were incubated overnight for double labelling with primary antibodies against mitochondrial complex IV subunit I and pro-SP-C, a marker for AECII (Table 1). The following morning, the sections were washed and incubated with the secondary antibodies (Table 1) for $2 \mathrm{~h}$ at room temperature. Double fluorescence samples were analyzed by confocal laser scanning microscopy (CLSM) with a Leica TCS SP5. (a, d, and g) Double IF stainings of AECII with their marker protein pro-SP-C. (b, e, and h) IF preparations for the mitochondrial complex IV subunit I. (c, f, and i) Double IF overlay for complex IV subunit I combined with pro-SP-C. NB, newborn; P15, postnatal day 15; AL, adult. Bars represent $20 \mu \mathrm{m}$.

samples from newborn (NB), P15, and adult (AL) mice showed an increase in the abundance of the mitochondrial complex IV subunit I in mitochondria in AECII during postnatal development. The abundance of complex IV subunit I gradually increased exhibiting the highest levels in the type II cells of the adult lungs (Figures $7(\mathrm{~g})-7(\mathrm{i})$ ) in comparison to the lungs from P15 (Figures $7(\mathrm{~d})-7(\mathrm{f})$ ) and newborn mice (Figures $7(\mathrm{a})-7(\mathrm{c})$ ). Despite lower abundance of mitochondrial complex IV subunit I, when compared to the mitochondrial complex IV subunit II, a gradual increase was observed in the newborn (Figures 8(a)-8(c)) and P15 animals (Figures 8(d)-8(f)). 


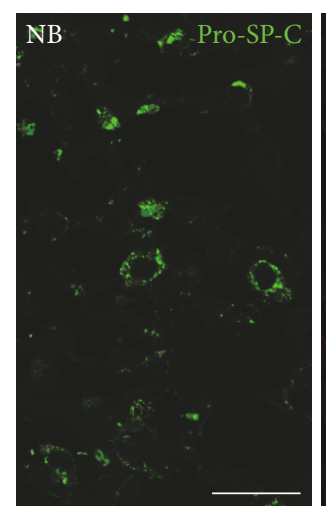

(a)

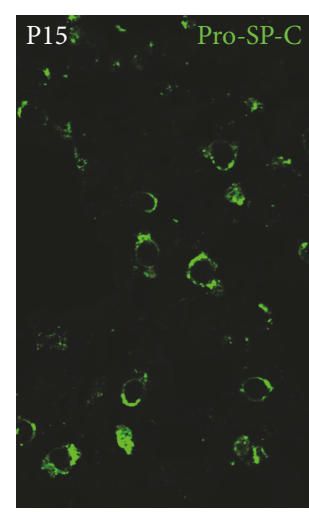

(d)

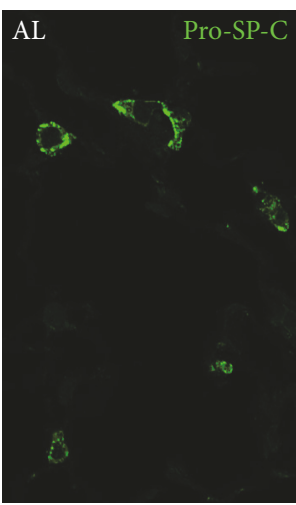

(g)

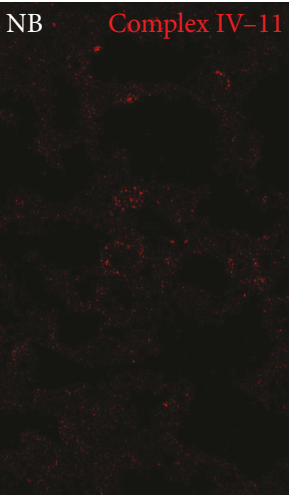

(b)

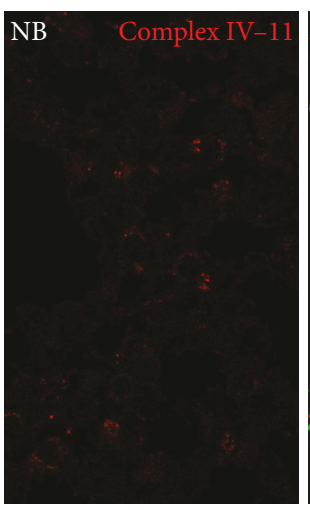

(e)

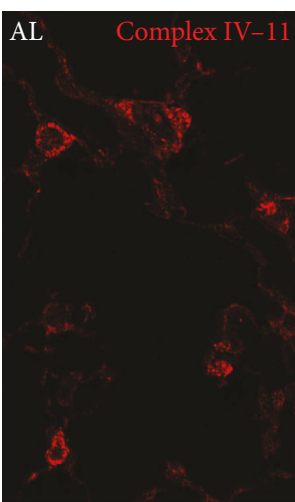

(h)

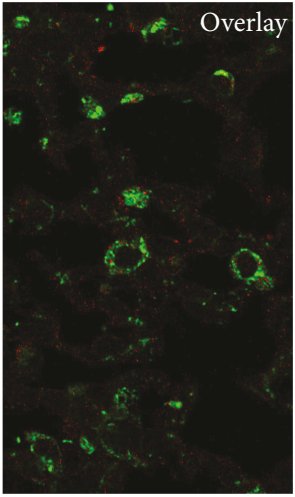

(c)

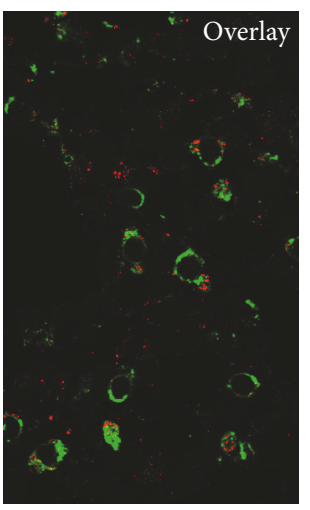

(f)

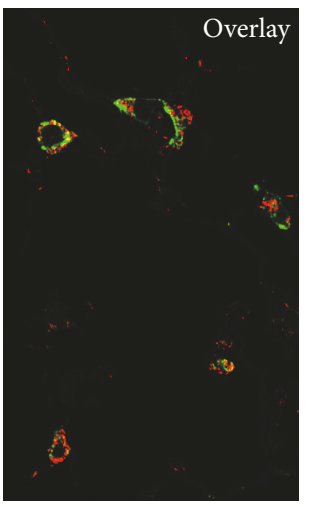

(i)

FIgURE 8: Representative immunofluorescence analysis of mitochondrial complex IV subunit II protein in AECII from lung tissue sections of newborn (NB), P15, and adult (AL) animals. Lung tissue samples from the three postnatal stages were embedded into paraffin. Thereafter, $3 \mu \mathrm{m}$ paraffin sections were cut with a rotation microtome and processed further for indirect double immunofluorescence.The lung sections were incubated overnight for double labelling with primary antibodies against mitochondrial complex IV subunit II and pro-SPC, a marker for AECII (Table 1). The following morning, the sections were washed and incubated with the secondary antibodies (Table 1) for $2 \mathrm{~h}$ at room temperature. Double fluorescence samples were analyzed by confocal laser scanning microscopy (CLSM) with a Leica TCS SP5. (a, d, and g) Double immunofluorescence stainings of AECII with their marker protein pro-SP-C. (b, e, and h) IF preparations for the mitochondrial complex IV subunit II. (c, f, and i) Double IF overlay for complex IV subunit II combined with pro-SP-C. NB, newborn; P15, postnatal day 15; AL, adult. Bars represent $20 \mu \mathrm{m}$.

High levels of complex IV subunit II were noted in mitochondria of AECII in adult animals (Figures 8(g)-8(i)). These differences in complex IV subunit abundance as observed in the IF preparations completely corroborated the Western blot results (Figure 1(a)) in lung tissue homogenates.
3.7. Postembedding Immunoelectron Microscopy for Different Mitochondrial Respiratory Complexes. In order to analyze the abundance of mitochondrial respiratory complex proteins on the ultrastructural level in individual mitochondria in lung tissue samples from newborn, P15, and adult mice, LR white-embedded lung ultrathin sections 


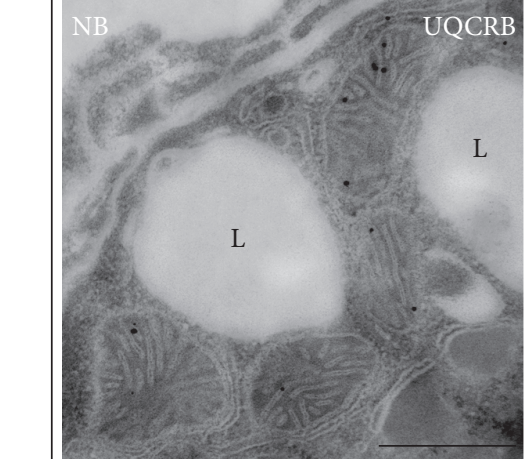

(a)

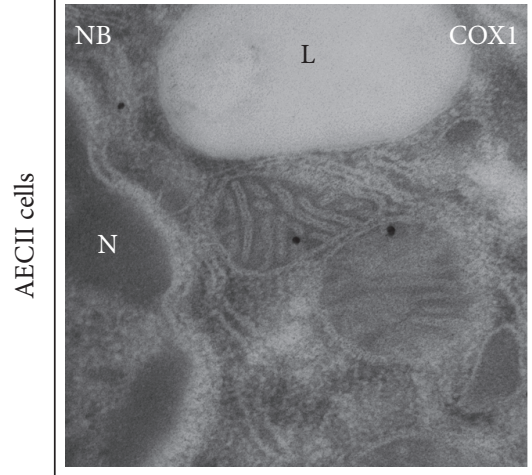

(d)

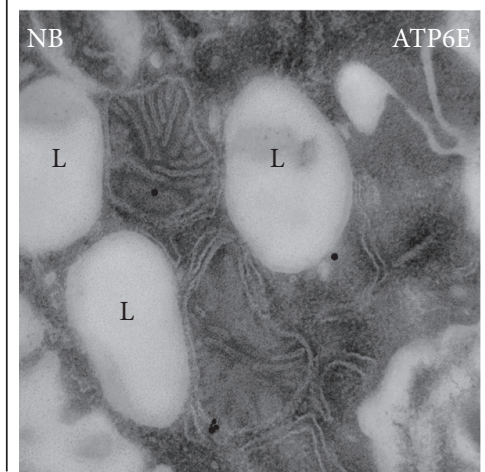

(g)

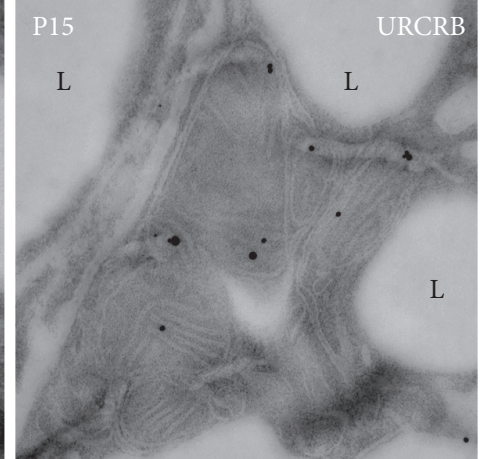

(b)

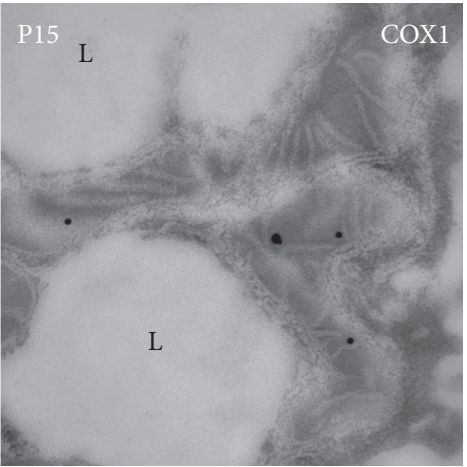

(e)

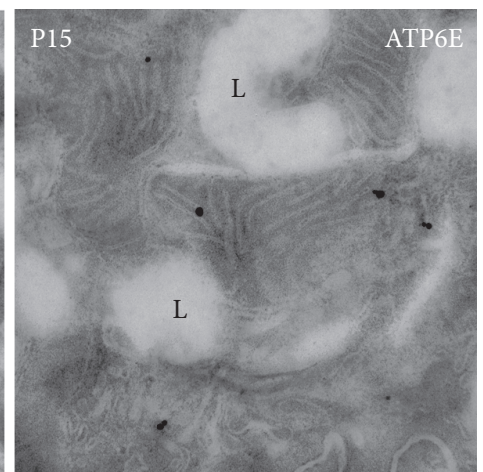

(h)

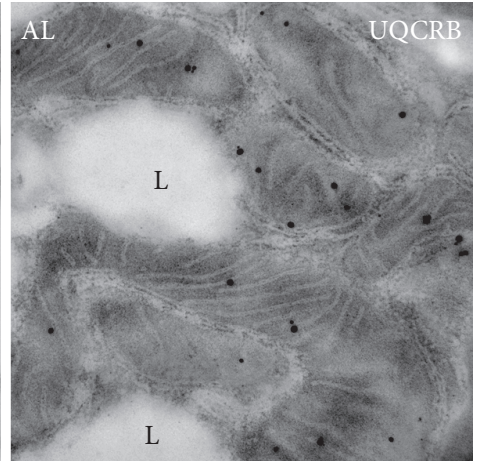

(c)

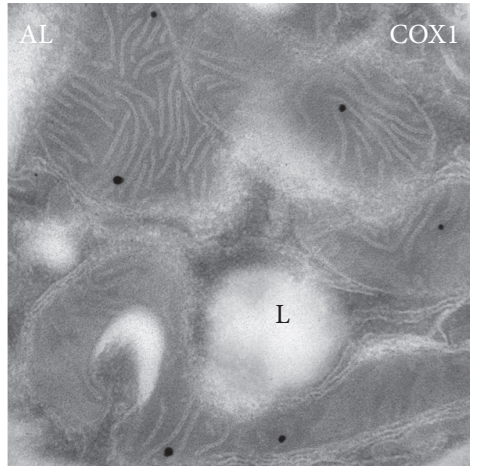

(f)

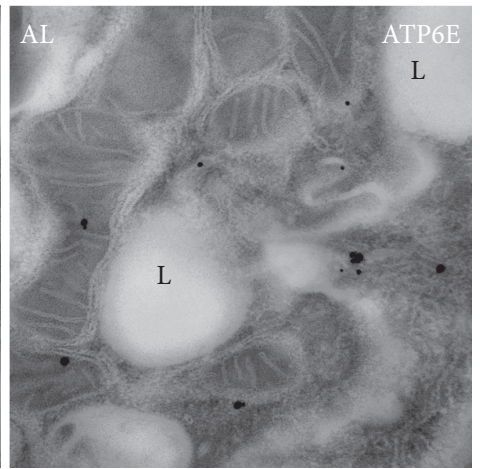

(i)

FIGURE 9: Electron micrographs showing immunogold labelling for mitochondrial proteins in ultrathin sections of AECII in newborn (NB), $\mathrm{P} 15$, and adult (AL) animals. Lung tissue processed for immunoelectron microscopy was incubated with gold-labelled secondary antibody particles and thereafter contrasted with uranyl acetate and lead citrate prior to analysis by transmission electron microscopy. (a-i) Immunogold labelling in mitochondria of AECII for (a-c) complex III (UQCR2), (d, e) complex IV (COX1), and (g, h) complex V (ATP6E). $S$, secretory granule; $L$, lamellar bodies. Bars represent $0.5 \mu \mathrm{m}$.

were processed by postembedding immunocytochemistry with the protein immunogold method and thereafter analyzed by TEM. As shown in (Figures 2, 9 and 10), gold particles clearly label mitochondria in the vicinity of their cristae, suggesting a high specificity of the antibodies used.

Due to the low abundance of many respiratory complexes in newborn animals and the use of the postembedding technique allowing mainly surface labelling, only few gold particles were present in mitochondria of AECII and ciliated cells in newborn mice (Figures 9-10(a), 10(d), and 10(j)). The gold particle number in mitochondria of club cells was even lower, resulting in labelling of few club cell mitochondria in newborn mice (Figures 2(a), 2(b), and 2(d)). A continuous gradual increase of the gold particle-labelling density occurred during later stages of postnatal development of AECII exhibiting the highest labelling density in the stainings with the antibody against complex III (UQCR2) (Figures 9(b) and 9(c)). In contrast to AECII, club cell (Figures 2(b) and 2(c)) and ciliated cell (Figures 10(b) and $10(\mathrm{c}))$ mitochondria showed significantly lower labelling for UQCR2 especially in the adult mice. We also noticed a postnatal gradual increase of the gold particle-labelling density for complex IV subunit I (COX1) in club cells (Figures 2(e) and 2(f)), AECII (Figures 9(e) and 9(f)), and 


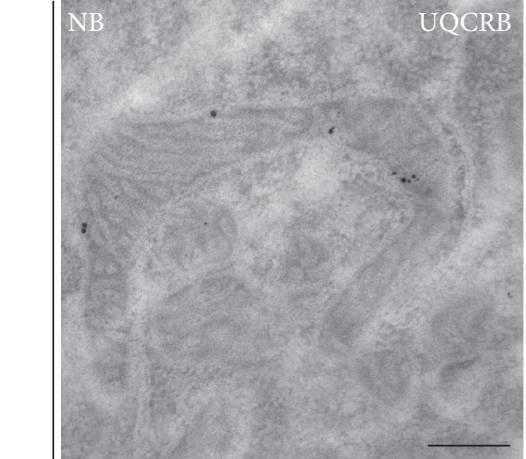

(a)

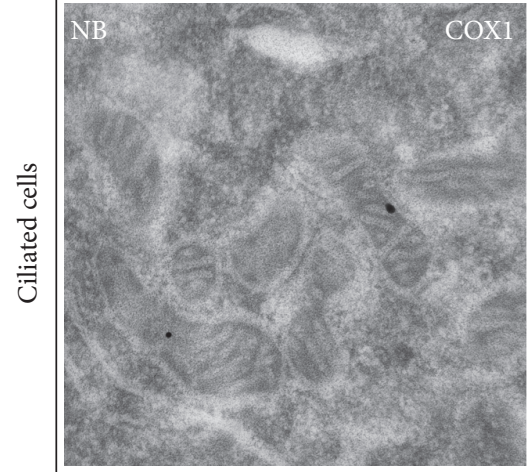

(d)

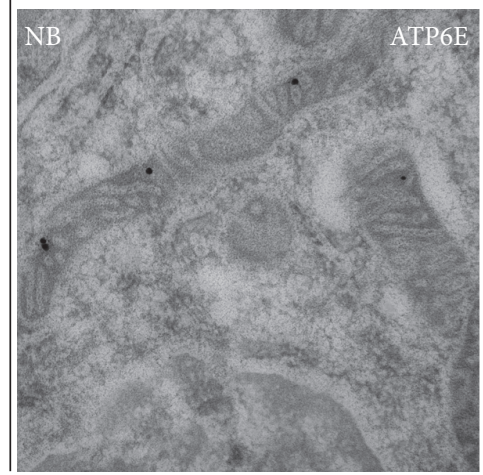

(g)

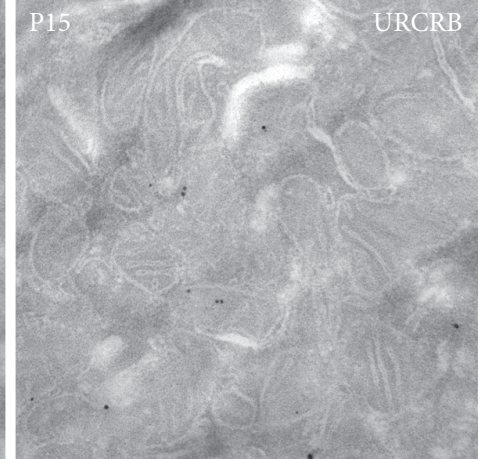

(b)

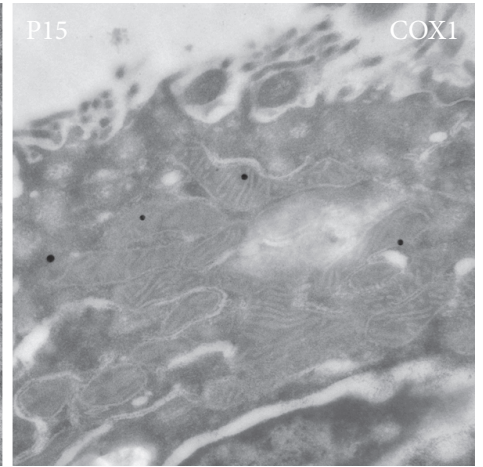

(e)

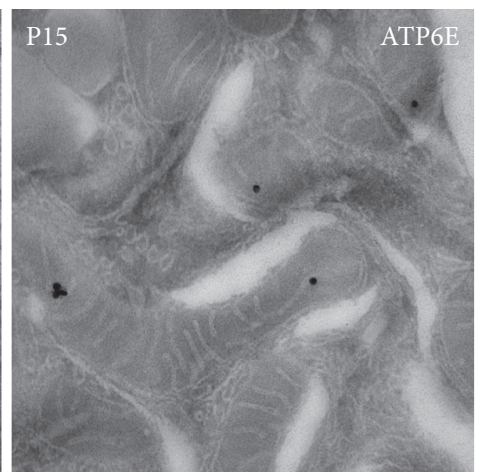

(h)

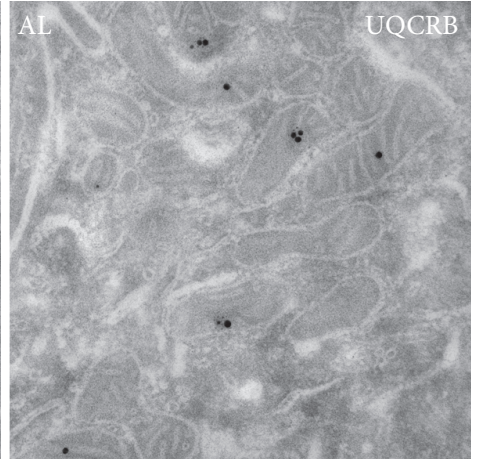

(c)

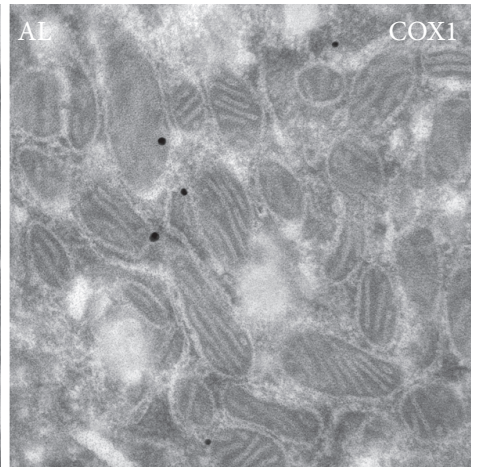

(f)

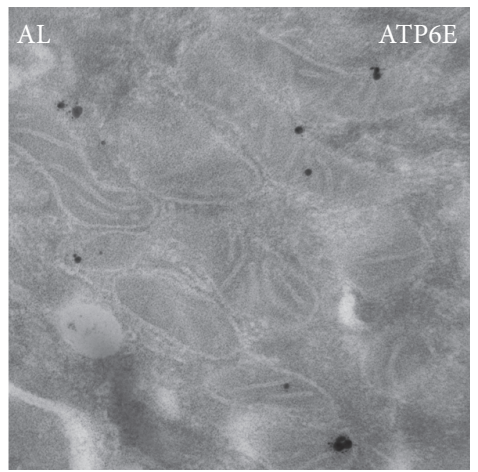

(i)

FIGURE 10: Electron micrographs showing immunogold labelling for mitochondrial proteins in ultrathin sections of ciliated cells in newborn (NB), P15, and adult (AL) animals. Lung tissue processed for immunoelectron microscopy was incubated with gold-labelled secondary antibody particles and thereafter contrasted with uranyl acetate and lead citrate prior to analysis by transmission electron microscopy. (a-i) Immunogold labelling in mitochondria of ciliated cells for (a-c) complex III (UQCR2), (d, e) complex IV (COX1), and $(\mathrm{g}, \mathrm{h})$ complex V (ATP6E). Bars represent $0.5 \mu \mathrm{m}$.

ciliated cells (Figures 10(e) and 10(f)). The intensity of the labelling for complex IV in all the three cell types was the lowest in comparison to that of complexes III and V. In addition to this, the gold particle labelling for complex $\mathrm{V}$ (ATP6E) as well increased postnatally in all the three cell types with the intensity of the labelling being very high in AECII (Figures 9(h) and 9(i)) in comparison to club cells (Figures 2(h) and 2(i)) and ciliated cells (Figures 10(h) and 10(i)). The negative controls of Figures 2, 9 and 10 are shown in Supplementary Figure 1 where no primary antibody was used and the micrographs remained completely devoid of staining suggesting a high specificity of the secondary antibody.

\section{Discussion}

Nearly all cell types in the lung depend on the metabolic activity of the mitochondria for their energy supply that is generated via the mitochondrial respiratory chain and oxidative phosphorylation (OXPHOS) [58, 59]. Hence, mitochondrial dysfunction can contribute to the pathophysiology of various pulmonary diseases such as bronchopulmonary dysplasia [60-62], chronic obstructive pulmonary disease (COPD) [63-65], lung cancer [66, 67], cystic fibrosis $[68,69]$, and asthma [70, 71]. This understanding of the human normal lung functioning and the mechanisms behind lung disease comes often from studies utilizing 
lung samples or animal models. Nowadays, frequently, mice are employed in lung research due to the advantages that this species provides [72, 73]. Surprisingly, only few reports are available from the literature concerning mitochondrial biogenesis, mitochondrial function, and the regulation of mtDNA genes during the postnatal lung development in mice. Most of the previously published data on the postnatal development of the mitochondrial compartment were described in other organs such as the liver, heart, blood lymphocytes, brain, skeletal muscle, or cell types. Therefore, we investigated the differential expression and cell type specific differences of distinct mitochondrial respiratory chain proteins and factors of the mitochondrial transcription and translation machinery during postnatal development of the mouse lung.

4.1. General Ultrastructure and Alterations of the Mitochondrial Compartment during Postnatal Development of Different Cell Types in the Lung as Revealed by Transmission Electron Microscopy. Clear differences were noted in general ultrastructure and the development of the mitochondrial compartment in distinct lung cell types (ciliated, club, and AECII) of the bronchiolar or the alveolar epithelium during postnatal mouse lung development. Similar to the club and AECII cells, TEM analysis of the ciliated cells revealed an elongation and an increase in the size of mitochondria starting from P15 in comparison to the newborns. In addition, this postnatal development of the ciliated cells was accompanied by a decrease in the cytoplasmic glycogen deposits. These morphological changes could imply the postnatal development of the ciliated cells. It was reported by Francis and coworkers [74] that mice are born with few ciliated cells in the trachea and that there is a postnatal increase in the ciliated cell density and cilia-generated flow in the trachea of the C57BL/6 mice from postnatal day 0 to day 28. Another study by Sorokin [75] described that the earliest ciliary motion was observed at postnatal days 5 to 7 in culture series of fetal rat lungs. Additionally, ciliary vibration after first being detected in the trachea and largest bronchi appears in the epithelium of smaller bronchial branches coinciding with the pattern of epithelial differentiation in the fetal lung [76]. Furthermore, our micrographs showed the distribution of mitochondria directly underneath the apical part of the cell, below the cilia. This distribution of mitochondria is necessary for the mammalian ATP-dependent ciliary beating [77].

TEM analysis of club cell ultrastructure in adult animals which showed a clear decrease in the proportion of cytoplasmic glycogen and a marked increase in the abundance of secretory granules in comparison to the club cells of the newborns reflecting their higher degree of maturation in comparison to newborn club cells. This finding is in accordance with studies from Plopper et al. [30] on the rabbit lung as well as from Baskerville [78] on the pig lung, reporting a decrease in the cytoplasmic glycogen abundance and a significant increase in the amount of electron-dense secretory granules postnatally. Plopper and coworkers suggested that the glycogen degradation would be required for energy production in order for a cell to initiate the important biogenesis processes such as biosynthesis of secretory products [30]. The cellular constituents of the club cells undergo significant shifts in organelle and glycogen deposit during differentiation, suggesting a metabolic shift from glycolysis to higher respiration. In addition to these signs of cellular maturation, we detected large and dense mitochondria which became more elongated but lost their cristae in the adult mouse club cells as compared to the P15 and newborn groups which is in agreement with a study in rat lung reporting that the mitochondria from adult club cells were more devoid of cristae in comparison to the neonates [79]. Newborn and P15 animals in our study showed a comparable ultrastructure, except for the appearance of secretory granules and a decrease in the number of cristae in the mitochondria of the club cells of P15 mice. The total number and volume of the club cells, the abundance and expression of the club cell secretory protein (CC10), and the volume of lung and bronchioles increased postnatally in P15 and adult mice in comparison to the newborns suggesting that club cell maturation occurs postnatally [54]. Collectively, all these findings reveal the postnatal differentiation and maturation of the club cells in the mouse lung.

Ultrastructural analysis of AECII also revealed a gradual decrease in glycogen amounts during the postnatal development. Additionally, our micrographs showed an increase in the number of lamellar bodies from the newborns to the P15 and adult animals. These results are in accordance with other findings on the development and maturation of AECII in the rat model [29]. Moreover, our data showed an increase in the mitochondrial length where more elongated mitochondria with longer and more densely packed lamellar cristae were observed in AECII from P15 and adult mice as compared to the newborn mice. These results are in agreement with published data on mitochondrial shape and volume in AECII of the lungs of Sprague-Dawley rats [29]. In previous articles using different animal species, it was suggested that this increase in the volume of mitochondria and change in its shape throughout the postnatal stages of development could be associated with the growing metabolic demands of the cell as well as with the production of a greater area-to-volume ratio [29, 32]. Furthermore, also in other organs, significant alterations of mitochondria were observed during postnatal development. For instance, Sato and colleagues detected larger and elongated mitochondria in the brain cortex of Wistar rats from postnatal day 5 with cristae reaching the maximal complexity in 15- and 21-day-old rats [52]. They speculated that this increase in the cristae complexity is correlated with the increase of respiratory enzyme activities in the membrane of the mitochondria. This change in the mitochondrial structure and shape in AECII and club cells is associated with morphological and functional differentiation of the cells as well as it is correlated with the total lung volume enlargement during the postnatal development. Similar to the club cells, AECII differentiate and mature postnatally where it was shown in rats that there is an increase in the fraction volume composition of AECII subcellular organelles (cytoplasm, mitochondria, and lamellar bodies) in adult Sprague-Dawley rats in comparison to the newborns [29]. Another study confirming the postnatal maturation of AECII 
in mice has shown that from E17.5 to P5 differentiation and maturation of AECII occurs that is associated with the ability of the cells to secrete surfactant [80].

Indeed, in our study, we were able to prove that mitochondrial respiratory complexes, as well as transcription factors and mitochondrial ribosomal RNA, were strongly upregulated during postnatal development. In the following, our results on alterations of respiratory complexes are compared in details to the international literature.

4.2. Complex I. Complex I is known as the largest complex of the mitochondrial respiratory chain which transfers electrons from $\mathrm{NADH}$ to coenzyme $\mathrm{Q}$ and uses this free energy to pump protons from the mitochondrial matrix into its intermembrane space $[81,82]$. The results of our study show a significant upregulation of mitochondrially encoded complex I gene as well as protein (MT-ND1) starting from the lungs of P15 mice and reaching the highest peak in the lungs of the adult mice. Comparable to our results, Bates and colleagues [51] detected a significant increase in the activity of complex I in the rat brain from postnatal day 1 to day 21 , suggesting that the increase is due to the high demand for mitochondrial ATP during the brain development. Interestingly, not only mitochondrially encoded complex I subunits increased in the expression during the postnatal development as was shown by our study but also the nuclear-encoded mitochondrial subunits as was revealed by Wirtz and Schuelke [53]. In their study on the expression of the 33 nuclear-encoded complex I genes during postnatal development of the C57BL/6J mouse brain, they found the rise of expression intensity of the complex I around P11 in comparison to earlier stages and this coincided with the synaptogenesis $[53,83-85]$. A more recent study of the mitochondria in the intrinsic muscle of Wistar rat tongue demonstrated a gradual increase in the mRNA expression of the mitochondrially encoded complex I subunit $m t-N d 1$ from birth to 15 days of age reaching the highest expression at 21 days of age [44]. Comparable results were observed from Fujita and Sato [44] for the level of NADH-O ${ }_{2}$ oxidoreductase activity in the intrinsic muscle of the Wistar rat tongue. They hypothesized that the hyperactivity in the NADH enzyme is indispensable for the transition from swallowing to mastication and that the increase in $m t-N d 1$ could be a result of this hyperactivity [44].

4.3. Complex II. Complex II is composed of 4 subunits which are encoded solely by nuclear DNA, with succinate dehydrogenase (SDH) being the largest subunit. This complex forms a direct link between the tricarboxylic acid (TCA) cycle and the respiratory chain [86]. Surprisingly, the only exception of the general mitochondrial maturation pattern was observed in our study for succinate dehydrogenase subunit $\mathrm{D}$ (SDHD) of complex II. We found that SDHD protein abundance peaked in the lung tissue samples from P15 mice and then decreased in the lungs from the adult animals. Moreover, although the mRNA expression of Sdhd was found to gradually increase starting from the lungs of P15 animals, the relative increase of this expression was the lowest among all the 5 complexes studied. Interestingly, our data are in agreement with the study by Valcarce and colleagues [28] that showed a strong increase in the postnatal SDH activity in the liver of albino Wistar rats until postnatal hour 6 , and afterwards, the activity of the SDH started to decline. It was suggested that this increase in mitochondrial enzyme activity is due to the increased rate of protein synthesis for mitochondrial enzymes after birth [28]. In a more recent study, Sato and colleagues [52] demonstrated as well an upregulation in the activity of $\mathrm{SDH}$, from the Wistar rat brain cortex that increased at 15 days postnatal, maintained at 21 days, and then decreased in mitochondria of adult animals. The reason behind this is not clearly understood, but several other studies showed a similar pattern of SDH activity. For instance, Sieck and Blanco [87] reported in their study on the postnatal changes in the succinate dehydrogenase activity in the diaphragm of cats that the muscle fiber SDH activity increased between 3 and 6 weeks postnatally declining thereafter to adult values. In addition, in a study on the postnatal development of complex II in mitochondria isolated from rat brain synaptosomes, an increase in the activities of complex II from day 10 to day 15 , without significant alterations of SHD activity thereafter, was reported [88].

4.4. Complex III. Complex III constitutes the central part of the mitochondrial respiratory chain and is composed of 11 different subunits where the cytochrome $\mathrm{b}$ gene $m t-C y b$ is the only complex III subunit encoded in the mitochondrial DNA (mtDNA) [89, 90]. Our data revealed a significant gradual upregulation in the expression of the $m t-C y t b$ mRNA in the lungs of the mice starting from postnatal day 15 (P15) in comparison to the lungs from the newborn animals. Our findings are in agreement with the results of the study from Marin-Garcia and colleagues [49] where they detected a 3and 4 -fold increase in the mRNA expression of $m t-C y t b$ in the bovine hearts of late fetal and young adult stages, respectively, in comparison to early fetal stages of development which correlated with the increase in mtDNA copy number. In addition to this, Schagger et al., in 1995, showed that the total protein amount of complex III and its catalytic activity was increased in the heart and liver tissue samples of Wistar rats during transition from fetal to adult stage correlating with the higher demands of oxidative phosphorylation activities in proliferating tissues [47]. Complex III activity was as well significantly upregulated in the mitochondria from the rat brain from postnatal day 1 to day 60 as was reported by Bates and colleagues [51].

4.5. Complex IV. Complex IV transfers the electrons from cytochrome $\mathrm{c}$ to molecular oxygen driving downstream ATP biosynthesis. It consists of 14 subunits, three of which ( $m t$-Co1, $m t$-Co2, and $m t$-Co3) are encoded by mitochondrial genome [91]. In our study, we analyzed the three mitochondrially encoded subunits (subunits I-III) of complex IV at the mRNA ( $m t-\mathrm{Co} 1, m t-\mathrm{Co} 2$, and $m t$-Co3) and protein (COX1, COX2) level and we found that the mRNA expression and abundance of this complex is drastically increased starting from the lungs of P15 mice. However, the increase in the abundance of these subunits, as shown by immunofluorescence and Western blot results, exhibited a different 
pattern of upregulation. The abundance of complex IV subunit I gradually increased displaying the highest levels in the type II cells of the adult lungs in comparison to the lungs from P15 and newborn mice. Similarly, a gradual increase in mitochondrial complex IV subunit II was as well observed; however, newborn and P15 animals exhibited lower levels of this protein in comparison to the labelling for subunit I. The increase in the expression and abundance of complex IV was the highest in comparison to other mitochondrial respiratory complexes. Moreover, we detected that complex IV, although upregulated in club and AECII cells, showed different levels of upregulation between these lung cell types as was shown by electron microscopy. There was a continuous gradual increase of the gold particle labelling during later stages of postnatal development; however, in contrast to AECII, club cell mitochondria exhibited significantly lower labelling for complex IV especially in adult mice. Our results are in accordance with other studies which as well detected the elevation of the complex IV during postnatal development of distinct species such as in the (1) Wistar rat hearts by Schagger and colleagues [47], (2) rat brain by Almeida et al. [88], (3) Wistar rat heart homogenates by Drahota and colleagues [48], (4) bovine heart tissues by Marin-Garcia and colleagues [49], and (5) liver and muscle COX activity in human samples by Pejznochova and colleagues suggesting that the maturation of the mitochondrial compartment is important for the differentiation of tissues and organs in mammals [92].

4.6. Complex V. Mitochondrial complex V, ATP synthase, is responsible for the synthesis of ATP from the ADP in the mitochondrial matrix using the provided energy from the proton electrochemical gradient $[93,94]$. Nearly no labelling for complex $\mathrm{V}$ was detected in the club cells of the newborn mice in comparison to the AECII in the newborns. Moreover, complex V showed a lower labelling in the club cell mitochondria of the adult mice as compared to the labelling in the AECII of adult animals. Our data on complex V are in agreement with a study in which isolated brain mitochondria of rats showed a significant increase in the activity of complex $\mathrm{V}$ starting from postnatal day 10 in comparison to the postnatal day 1 [51]. Similarly, Marin-Garcia and colleagues showed an increase in the expression of ATP- $\beta$ Synthase mRNA in the bovine heart tissue from the late fetal and young adult animals [49].

4.7. Associated Mitochondrial Transcription Machinery and Mitochondrial rRNAs. It is known that the initiation of mitochondrial transcription needs nucleus-encoded proteins, such as POLRMT, auxiliary factors for promoter recognition, such as TFB1M and TFB2M, and promoter activation like Tfam [95-97]. These factors are required for the transcription of mtDNA that controls the rRNA/mRNA ratio. We have noticed that the regulation of the machinery required for the maintenance and expression of mtDNA showed a significant increase from postnatal day 15 to the adult stage in comparison to the newborn mice. These results are in accordance with earlier study showing a postnatal increase in the mtDNA content in the mouse lung during the first
2 months, followed by a moderate decline at 5 months and then an increase again by 15 months of age [98]. This increase in mtDNA level is associated with periods of increased susceptibility of the tissues to oxidative stress and injury during the early life and advance stages [98]. Likewise, an increase in the expression of the mitochondrial transcription factor (TFB2M) and the mitochondrial RNA polymerase (POLRMT) in growing rat hearts was shown in adult and aged animals [99] suggesting of an increase is the mitochondrial biogenesis in maturing cardiomyocytes which fits the role of TFB2M as an accessory subunit of POLRMT required for promoter recognition [100, 101]. However, in contrast to our study, they showed that RNA expression and protein abundance of TFAM remained constant throughout life and this might be due to the fact that TFAM levels are correlated with the amount of mtDNA in the cell [99]. TFAM is an mtDNA-binding protein required for the transcription of mtDNA and is thought to act as mtDNA copy number regulator [102, 103]. It was suggested, in this study, that rats, apparently, do not need an increase in mtDNA in order to cope with increased mitochondrial biogenesis during the postnatal heart development. In addition to this, Pohjoismäki and colleagues [99] also showed an elevation in the expression of Polg2 in 10-dayold rats as compared to neonates. Mitochondrially encoded RNA (rRNA) is necessary for mitochondrial protein biosynthesis. After mtDNA is transcribed, mitochondria translate their mRNA on mitochondrial ribosomes consisting of 2 mtDNA-encoded rRNAs and nuclear-encoded proteins [104]. Our results report an increase in the expression of mitochondrial rRNA during the postnatal development of murine lungs. This increase in the expression is reasonable as it emphasizes the upregulation of the mitochondrial translation machinery and mitochondrial expression systems during the postnatal development showing that the cells are still proliferating.

\section{Conclusions}

In this article, we show that the alterations of the mitochondrial compartment with special focus on mitochondrial respiratory complexes and associated mitochondrial transcription machinery as well as mitochondrial rRNAs exhibited a specific adaptation and differential maturation of the mitochondrial compartment according to the metabolic needs of individual cell types during postnatal development of the mouse lung.

\section{Conflicts of Interest}

The authors declare that they have no conflicts of interest.

\section{Authors' Contributions}

Eveline Baumgart-Vogt and Srikanth Karnati designed the research. Natalia El-Merhie, Susanne Pfreimer, Bianca Pfeiffer, Oleg Pak, Djuro Kosanovic, Michael Seimetz, and Srikanth Karnati performed the research. Eveline Baumgart-Vogt, Adrian Pilatz, Ralph Theo Schermuly, 
Norbert Weissmann, and Srikanth Karnati contributed reagents, materials, and analysis tools. Eveline BaumgartVogt and Adrian Pilatz contributed the budget to the study. Natalia El-Merhie, Susanne Pfreimer, Bianca Pfeiffer, and Srikanth Karnati acquired the data. Natalia El-Merhie, Eveline Baumgart-Vogt, and Srikanth Karnati analyzed and interpreted the data. Natalia El-Merhie, Eveline Baumgart-Vogt, and Srikanth Karnati wrote the paper. Eveline Baumgart-Vogt and Srikanth Karnati conceived and supervised the study.

\section{Acknowledgments}

This study was supported by LOM (Leistungsorientierte Mittel) performance-related resource allocation funds of the Medical Faculty of the Justus Liebig Universität Gießen, Germany.

\section{Supplementary Materials}

Supplementary Figure 1: Electron micrograph of the negative control (NC) for Figures 8-10. (A-C) Ciliated cells, (D-F) club cells, and (G-I) AECII of newborn (NB), P15, and adult (AL) animals. (Supplementary Materials)

\section{References}

[1] R. A. Gottlieb, "Mitochondria: execution central," FEBS Letters, vol. 482, no. 1-2, pp. 6-12, 2000.

[2] S. Elmore, "Apoptosis: a review of programmed cell death," Toxicologic Pathology, vol. 35, no. 4, pp. 495-516, 2007.

[3] C. Ott, K. Ross, S. Straub et al., "Sam50 functions in mitochondrial intermembrane space bridging and biogenesis of respiratory complexes," Molecular and Cellular Biology, vol. 32, no. 6, pp. 1173-1188, 2012.

[4] B. Aravamudan, M. A. Thompson, C. M. Pabelick, and Y. S. Prakash, "Mitochondria in lung diseases," Expert Review of Respiratory Medicine, vol. 7, no. 6, pp. 631-646, 2013.

[5] P. Mitchell, "Coupling of phosphorylation to electron and hydrogen transfer by a chemi-osmotic type of mechanism," Nature, vol. 191, pp. 144-148, 1961.

[6] H. Yang, T. Yang, J. A. Baur et al., "Nutrient-sensitive mitochondrial $\mathrm{NAD}^{+}$levels dictate cell survival," Cell, vol. 130, no. 6, pp. 1095-1107, 2007.

[7] H. S. Sherratt and D. M. Turnbull, "6 mitochondrial oxidations and ATP synthesis in muscle," Baillière's Clinical Endocrinology and Metabolism, vol. 4, no. 3, pp. 523-560, 1990.

[8] E. R. Roberts and K. J. Thomas, "The role of mitochondria in the development and progression of lung cancer," Computational and Structural Biotechnology Journal, vol. 6, no. 7, article e201303019, 2013.

[9] J. Smeitink, L. van den Heuvel, and S. DiMauro, "The genetics and pathology of oxidative phosphorylation," Nature Reviews Genetics, vol. 2, no. 5, pp. 342-352, 2001.

[10] D. C. Chan, "Mitochondria: dynamic organelles in disease, aging, and development," Cell, vol. 125, no. 7, pp. 12411252, 2006.

[11] P. Mishra and D. C. Chan, "Mitochondrial dynamics and inheritance during cell division, development and disease,"
Nature Reviews Molecular Cell Biology, vol. 15, no. 10, pp. 634-646, 2014.

[12] V. Soubannier, G. L. McLelland, R. Zunino et al., "A vesicular transport pathway shuttles cargo from mitochondria to lysosomes," Current Biology, vol. 22, no. 2, pp. 135-141, 2012.

[13] R. Bravo-Sagua, A. E. Rodriguez, J. Kuzmicic et al., "Cell death and survival through the endoplasmic reticulummitochondrial axis," Current Molecular Medicine, vol. 13, no. 2, pp. 317-329, 2013.

[14] E. Gottlieb, S. M. Armour, M. H. Harris, and C. B. Thompson, "Mitochondrial membrane potential regulates matrix configuration and cytochrome c release during apoptosis," Cell Death and Differentiation, vol. 10, no. 6, pp. 709-717, 2003.

[15] P. Ghafourifar and C. Richter, "Nitric oxide synthase activity in mitochondria," FEBS Letters, vol. 418, no. 3, pp. 291-296, 1997.

[16] E. N. Dedkova, X. Ji, S. L. Lipsius, and L. A. Blatter, "Mitochondrial calcium uptake stimulates nitric oxide production in mitochondria of bovine vascular endothelial cells," American Journal of Physiology - Cell Physiology, vol. 286, no. 2, pp. C406-C415, 2004.

[17] R. Radi, A. Cassina, R. Hodara, C. Quijano, and L. Castro, "Peroxynitrite reactions and formation in mitochondria," Free Radical Biology \& Medicine, vol. 33, no. 11, pp. 14511464, 2002.

[18] C. Quijano, D. Hernandez-Saavedra, L. Castro, J. M. McCord, B. A. Freeman, and R. Radi, "Reaction of peroxynitrite with Mn-superoxide dismutase. Role of the metal center in decomposition kinetics and nitration," The Journal of Biological Chemistry, vol. 276, no. 15, pp. 11631-11638, 2001.

[19] Y. H. Wei and H. C. Lee, "Oxidative stress, mitochondrial DNA mutation, and impairment of antioxidant enzymes in aging," Experimental Biology and Medicine, vol. 227, no. 9, pp. 671-682, 2002.

[20] H. Zhang, Y. M. Go, and D. P. Jones, "Mitochondrial thioredoxin-2/peroxiredoxin-3 system functions in parallel with mitochondrial GSH system in protection against oxidative stress," Archives of Biochemistry and Biophysics, vol. 465, no. 1, pp. 119-126, 2007.

[21] D. P. Jones, "Radical-free biology of oxidative stress," American Journal of Physiology - Cell Physiology, vol. 295, no. 4, pp. C849-C868, 2008.

[22] S. Immenschuh, E. Baumgart-Vogt, M. Tan, S. Iwahara, G. Ramadori, and H. D. Fahimi, "Differential cellular and subcellular localization of heme-binding protein 23/peroxiredoxin I and heme oxygenase- 1 in rat liver," Journal of Histochemistry \& Cytochemistry, vol. 51, no. 12, pp. 1621-1631, 2003.

[23] L. Flohe and W. Schlegel, "Glutathione peroxidase. IV. Intracellular distribution of the glutathione peroxidase system in the rat liver," Hoppe-Seyler's Zeitschrift fur Physiologische Chemie, vol. 352, no. 10, pp. 1401-1410, 1971.

[24] C. Giorgi, C. Agnoletto, A. Bononi et al., "Mitochondrial calcium homeostasis as potential target for mitochondrial medicine," Mitochondrion, vol. 12, pp. 77-85, 2009.

[25] K. E. Wellen, G. Hatzivassiliou, U. M. Sachdeva, T. V. Bui, J. R. Cross, and C. B. Thompson, "ATP-citrate lyase links cellular metabolism to histone acetylation," Science, vol. 324, no. 5930, pp. 1076-1080, 2009.

[26] R. Sutton and J. K. Pollak, "Hormone-initiated maturation of rat liver mitochondria after birth," Biochemical Journal, vol. 186, no. 1, pp. 361-367, 1980. 
[27] J. K. Pollak and R. Sutton, "The differentiation of animal mitochondria during development," Trends in Biochemical Sciences, vol. 5, pp. 23-27, 1980.

[28] C. Valcarce, R. M. Navarrete, P. Encabo, E. Loeches, J. Satrustegui, and J. M. Cuezva, "Postnatal development of rat liver mitochondrial functions. The roles of protein synthesis and of adenine nucleotides," The Journal of Biological Chemistry, vol. 263, no. 16, pp. 7767-7775, 1988.

[29] S. L. Young, E. K. Fram, C. L. Spain, and E. W. Larson, "Development of type II pneumocytes in rat lung," American Journal of Physiology - Lung Cellular and Molecular Physiology, vol. 260, no. 2, Part 1, pp. L113-L122, 1991.

[30] C. G. Plopper, J. L. Alley, C. J. Serabjitsingh, and R. M. Philpot, "Cytodifferentiation of the nonciliated bronchiolar epithelial (Clara) cell during rabbit lung maturation: an ultrastructural and morphometric study," American Journal of Anatomy, vol. 167, no. 3, pp. 329-357, 1983.

[31] G. D. Massaro and D. Massaro, "Development of bronchiolar epithelium in rats," American Journal of Physiology Regulatory, Integrative and Comparative Physiology, vol. 250, no. 5, Part 2, pp. R783-R788, 1986.

[32] D. M. Hyde, C. G. Plopper, P. H. Kass, and J. L. Alley, "Estimation of cell numbers and volumes of bronchiolar epithelium during rabbit lung maturation," American Journal of Anatomy, vol. 167, no. 3, pp. 359-370, 1983.

[33] H. B. Suliman, K. E. Welty-Wolf, M. Carraway, L. Tatro, and C. A. Piantadosi, "Lipopolysaccharide induces oxidative cardiac mitochondrial damage and biogenesis," Cardiovascular Research, vol. 64, no. 2, pp. 279-288, 2004.

[34] D. C. Simoes, A. M. Psarra, T. Mauad et al., "Glucocorticoid and estrogen receptors are reduced in mitochondria of lung epithelial cells in asthma," PLoS One, vol. 7, no. 6, article e39183, 2012.

[35] S. Mishra, L. C. Murphy, and L. J. Murphy, "The Prohibitins: emerging roles in diverse functions," Journal of Cellular and Molecular Medicine, vol. 10, no. 2, pp. 353-363, 2006.

[36] D. Liu, Y. Lin, T. Kang et al., "Mitochondrial dysfunction and adipogenic reduction by prohibitin silencing in 3T3-L1 cells," PLoS One, vol. 7, no. 3, artilce e34315, 2012.

[37] N. Soulitzis, E. Neofytou, M. Psarrou et al., "Downregulation of lung mitochondrial prohibitin in COPD," Respiratory Medicine, vol. 106, no. 7, pp. 954-961, 2012.

[38] K. Mizumura, S. M. Cloonan, K. Nakahira et al., "Mitophagydependent necroptosis contributes to the pathogenesis of COPD," The Journal of Clinical Investigation, vol. 124, no. 9, pp. 3987-4003, 2014.

[39] M. Levy and R. Toury, "Study on the evolution of mitochondrial enzyme activities in hepatocyte during rat development," Biochimica et Biophysica Acta (BBA) - Bioenergetics, vol. 216, no. 2, pp. 318-327, 1970.

[40] J. K. Pollak, "The maturation of the inner membrane of foetal rat liver mitochondria. An example of a positive-feedback mechanism," Biochemical Journal, vol. 150, no. 3, pp. 477488, 1975.

[41] J. R. Aprille and G. K. Asimakis, "Postnatal development of rat liver mitochondria: state 3 respiration, adenine nucleotide translocase activity, and the net accumulation of adenine nucleotides," Archives of Biochemistry and Biophysics, vol. 201, no. 2, pp. 564-575, 1980.

[42] J. B. Krahling, R. Gee, J. A. Gauger, and N. E. Tolbert, "Postnatal development of peroxisomal and mitochondrial enzymes in rat liver," Journal of Cellular Physiology, vol. 101, no. 3, pp. 375-390, 1979.

[43] C. A. Lang, "Respiratory enzymes in the heart and liver of the prenatal and postnatal rat," Biochemical Journal, vol. 95, pp. 365-371, 1965.

[44] T. Fujita and I. Sato, "NADH- $\mathrm{O}_{2}$ oxidoreductase activity and mRNA expression of complex I (51 kDa, ND1) in postnatal intrinsic muscle of rat tongue," Journal of Anatomy, vol. 202, no. 2, pp. 205-212, 2003.

[45] I. Schmidt and P. Herpin, "Postnatal changes in mitochondrial protein mass and respiration in skeletal muscle from the newborn pig," Comparative Biochemistry and Physiology Part B: Biochemistry and Molecular Biology, vol. 118, no. 3, pp. 639-647, 1997.

[46] W. J. Wolf, K. A. Rex, E. Geshi, and L. A. Sordahl, "Postnatal changes in heart mitochondrial calcium and energy metabolism," American Journal of Physiology - Heart and Circulatory Physiology, vol. 261, no. 1, Part 2, pp. H1-H8, 1991.

[47] H. Schagger, H. Noack, W. Halangk, U. Brandt, and G. von Jagow, "Cytochrome- $c$ oxidase in developing rat heart enzymic properties and amino-terminal sequences suggest identity of the fetal heart and the adult liver isoform," European Journal of Biochemistry, vol. 230, no. 1, pp. 235241, 1995.

[48] Z. Drahota, M. Milerova, A. Stieglerova, J. Houstek, and B. Ostadal, "Developmental changes of cytochrome c oxidase and citrate synthase in rat heart homogenate," Physiological Research, vol. 53, no. 1, pp. 119-122, 2004.

[49] J. Marin-Garcia, R. Ananthakrishnan, N. Agrawal, and M. J. Goldenthal, "Mitochondrial gene expression during bovine cardiac growth and development," Journal of Molecular and Cellular Cardiology, vol. 26, no. 8, pp. 1029-1036, 1994.

[50] U. Ernstroem and B. Larsson, "The postnatal development of the mitochondrial contents in blood lymphocytes of normal and oxygen-exposed mice," Acta Pathologica Microbiologica Scandinavica, vol. 59, pp. 481-484, 1963.

[51] T. E. Bates, A. Almeida, S. J. Heales, and J. B. Clark, "Postnatal development of the complexes of the electron transport chain in isolated rat brain mitochondria," Developmental Neuroscience, vol. 16, no. 5-6, pp. 321-327, 1994.

[52] I. Sato, K. Konishi, A. Mikami, and T. Sato, "Developmental changes in enzyme activities and in morphology of rat cortex mitochondria," Okajimas Folia Anatomica Japonica, vol. 76, no. 6, pp. 353-361, 2000.

[53] S. Wirtz and M. Schuelke, "Region-specific expression of mitochondrial complex I genes during murine brain development," PLoS One, vol. 6, no. 4, article e18897, 2011.

[54] S. Karnati, T. Graulich, G. Oruqaj et al., "Postnatal development of the bronchiolar club cells of distal airways in the mouse lung: stereological and molecular biological studies," Cell and Tissue Research, vol. 364, no. 3, pp. 543-557, 2016.

[55] S. Karnati and E. Baumgart-Vogt, "Peroxisomes in mouse and human lung: their involvement in pulmonary lipid metabolism," Histochemistry and Cell Biology, vol. 130, no. 4, pp. 719-740, 2008.

[56] S. Karnati and E. Baumgart-Vogt, "Peroxisomes in airway epithelia and future prospects of these organelles for pulmonary cell biology," Histochemistry and Cell Biology, vol. 131, no. 4, pp. 447-454, 2009.

[57] G. Danscher and J. O. Norgaard, "Light microscopic visualization of colloidal gold on resin-embedded tissue," The 
Journal of Histochemistry and Cytochemistry, vol. 31, no. 12, pp. 1394-1398, 1983.

[58] A. B. Fisher, A. Scarpa, K. F. LaNoue, D. Bassett, and J. R. Williamson, "Respiration of rat lung mitochondria and the influence of $\mathrm{Ca}^{2+}$ on substrate utilization," Biochemistry, vol. 12, no. 7, pp. 1438-1445, 1973.

[59] V. Natarajan and N. L. Parinandi, Eds., Mitochondrial Function in Lung Health and Disease, Humana Press, New York, New York, USA, 2014.

[60] R. L. Morton, D. Ikle, and C. W. White, "Loss of lung mitochondrial aconitase activity due to hyperoxia in bronchopulmonary dysplasia in primates," American Journal of Physiology - Lung Cellular and Molecular Physiology, vol. 274, no. 1, Part 1, pp. L127-L133, 1998.

[61] V. Ratner, S. A. Sosunov, Z. V. Niatsetskaya, I. V. UtkinaSosunova, and V. S. Ten, "Mechanical ventilation causes pulmonary mitochondrial dysfunction and delayed alveolarization in neonatal mice," American Journal of Respiratory Cell and Molecular Biology, vol. 49, no. 6, pp. 943-950, 2013.

[62] V. Ratner, A. Starkov, D. Matsiukevich, R. A. Polin, and V. S. Ten, "Mitochondrial dysfunction contributes to alveolar developmental arrest in hyperoxia-exposed mice," American Journal of Respiratory Cell and Molecular Biology, vol. 40, no. 5, pp. 511-518, 2009.

[63] P. A. Kirkham and P. J. Barnes, "Oxidative stress in COPD," Chest, vol. 144, no. 1, pp. 266-273, 2013.

[64] A. Meyer, J. Zoll, A. L. Charles et al., "Skeletal muscle mitochondrial dysfunction during chronic obstructive pulmonary disease: central actor and therapeutic target," Experimental Physiology, vol. 98, no. 6, pp. 1063-1078, 2013.

[65] H. Hara, J. Araya, S. Ito et al., "Mitochondrial fragmentation in cigarette smoke-induced bronchial epithelial cell senescence," American Journal of Physiology - Lung Cellular and Molecular Physiology, vol. 305, no. 10, pp. L737-L746, 2013.

[66] D. W. Kamp, E. Shacter, and S. A. Weitzman, "Chronic inflammation and cancer: the role of the mitochondria," Oncology, vol. 25, no. 5, pp. 400-410, 2011, 413.

[67] S. S. Yang Ai, K. Hsu, C. Herbert et al., "Mitochondrial DNA mutations in exhaled breath condensate of patients with lung cancer," Respiratory Medicine, vol. 107, no. 6, pp. 911-918, 2013.

[68] B. L. Shapiro, "Mitochondrial dysfunction, energy expenditure, and cystic fibrosis," The Lancet, vol. 2, no. 8605, p. 289, 1988.

[69] B. L. Shapiro, R. J. Feigal, and L. F. Lam, "Mitrochondrial NADH dehydrogenase in cystic fibrosis," Proceedings of the National Academy of Sciences of the United States of America, vol. 76, no. 6, pp. 2979-2983, 1979.

[70] A. Heinzmann, C. Thoma, H. Dietrich, and K. A. Deichmann, "Identification of common polymorphisms in the mitochondrial genome," Allergy, vol. 58, no. 8, pp. 830-831, 2003.

[71] M. Jones, P. Mitchell, J. J. Wang, and C. Sue, "MELAS A3243G mitochondrial DNA mutation and age related maculopathy," American Journal of Ophthalmology, vol. 138, no. 6, pp. 1051-1053, 2004.

[72] E. W. Gelfand, "Mice are a good model of human airway disease," American Journal of Respiratory and Critical Care Medicine, vol. 166, no. 1, pp. 5-6, 2002.

[73] J. M. Drazen, P. W. Finn, and G. T. De Sanctis, "Mouse models of airway responsiveness: physiological basis of observed outcomes and analysis of selected examples using these outcome indicators," Annual Review of Physiology, vol. 61, pp. 593-625, 1999.

[74] R. J. Francis, B. Chatterjee, N. T. Loges, H. Zentgraf, H. Omran, and C. W. Lo, "Initiation and maturation of cilia-generated flow in newborn and postnatal mouse airway," American Journal of Physiology - Lung Cellular and Molecular Physiology, vol. 296, no. 6, pp. L1067-L1075, 2009.

[75] S. P. Sorokin, "Centriole formation and ciliogenesis," Aspen Emphysema Conference, vol. 11, pp. 213-216, 1968.

[76] S. P. Sorokin, "Reconstructions of centriole formation and ciliogenesis in mammalian lungs," Journal of Cell Science, vol. 3, no. 2, pp. 207-230, 1968.

[77] M. Salathe, "Regulation of mammalian ciliary beating," Annual Review of Physiology, vol. 69, pp. 401-422, 2007.

[78] A. Baskerville, "Ultrastructural studies of the normal pulmonary tissue of the pig," Research in Veterinary Science, vol. 11, no. 2, pp. 150-155, 1970.

[79] P. Smith, D. Heath, and H. Moosavi, “The Clara cell," Thorax, vol. 29, no. 2, pp. 147-163, 1974.

[80] H. Fehrenbach, "Alveolar epithelial type II cell: defender of the alveolus revisited," Respiratory Research, vol. 2, no. 1, pp. 33-46, 2001.

[81] J. E. Walker, "The NADH:ubiquinone oxidoreductase (complex I) of respiratory chains," Quarterly Reviews of Biophysics, vol. 25, no. 3, pp. 253-324, 1992.

[82] R. G. Efremov, R. Baradaran, and L. A. Sazanov, "The architecture of respiratory complex I,” Nature, vol. 465, no. 7297, pp. 441-445, 2010.

[83] J. Pokorny and T. Yamamoto, "Postnatal ontogenesis of hippocampal CA1 area in rats. I. Development of dendritic arborisation in pyramidal neurons," Brain Research Bulletin, vol. 7, no. 2, pp. 113-120, 1981.

[84] J. Pokorny and T. Yamamoto, "Postnatal ontogenesis of hippocampal CA1 area in rats. II. Development of ultrastructure in stratum lacunosum and moleculare," Brain Research Bulletin, vol. 7, no. 2, pp. 121-130, 1981.

[85] M. Mody, Y. Cao, Z. Cui et al., "Genome-wide gene expression profiles of the developing mouse hippocampus," Proceedings of the National Academy of Sciences of the United States of America, vol. 98, no. 15, pp. 8862-8867, 2001.

[86] G. Cecchini, "Function and structure of complex II of the respiratory chain," Annual Review of Biochemistry, vol. 72, pp. 77-109, 2003.

[87] G. C. Sieck and C. E. Blanco, "Postnatal changes in the distribution of succinate dehydrogenase activities among diaphragm muscle fibers," Pediatric Research, vol. 29, no. 6, pp. 586-593, 1991.

[88] A. Almeida, K. J. Brooks, I. Sammut et al., "Postnatal development of the complexes of the electron transport chain in synaptic mitochondria from rat brain," Developmental Neuroscience, vol. 17, no. 4, pp. 212-218, 1995.

[89] A. R. Crofts, J. T. Holland, D. Victoria et al., "The Q-cycle reviewed: how well does a monomeric mechanism of the $b c_{1}$ complex account for the function of a dimeric complex?," Biochimica et Biophysica Acta (BBA) - Bioenergetics, vol. 1777, no. 7-8, pp. 1001-1019, 2008.

[90] H. Schagger, T. A. Link, W. D. Engel, and G. von Jagow, "Isolation of the eleven protein subunits of the $b c_{1}$ complex from beef heart," Methods in Enzymology, vol. 126, pp. 224237, 1986. 
[91] R. A. Capaldi, "Structure and function of cytochrome $c$ oxidase," Annual Review of Biochemistry, vol. 59, pp. 569596, 1990.

[92] M. Pejznochova, M. Tesarova, H. Hansikova et al., "Mitochondrial DNA content and expression of genes involved in mtDNA transcription, regulation and maintenance during human fetal development," Mitochondrion, vol. 10, no. 4, pp. 321-329, 2010.

[93] R. A. Capaldi, R. Aggeler, P. Turina, and S. Wilkens, "Coupling between catalytic sites and the proton channel in $\mathrm{F}_{1} \mathrm{~F}_{0}$-type ATPases," Trends in Biochemical Sciences, vol. 19, no. 7, pp. 284-289, 1994.

[94] M. Zeviani and S. Di Donato, "Mitochondrial disorders," Brain, vol. 127, no. 10, pp. 2153-2172, 2004.

[95] D. Ojala, J. Montoya, and G. Attardi, "tRNA punctuation model of RNA processing in human mitochondria," Nature, vol. 290, no. 5806, pp. 470-474, 1981.

[96] B. S. Masters, L. L. Stohl, and D. A. Clayton, "Yeast mitochondrial RNA polymerase is homologous to those encoded by bacteriophages T3 and T7," Cell, vol. 51, no. 1, pp. 8999, 1987.

[97] M. Falkenberg, M. Gaspari, A. Rantanen, A. Trifunovic, N. G. Larsson, and C. M. Gustafsson, "Mitochondrial transcription factors B1 and B2 activate transcription of human mtDNA," Nature Genetics, vol. 31, no. 3, pp. 289-294, 2002.

[98] M. Masuyama, R. Iida, H. Takatsuka, T. Yasuda, and T. Matsuki, "Quantitative change in mitochondrial DNA content in various mouse tissues during aging," Biochimica et Biophysica Acta (BBA) - General Subjects, vol. 1723, no. 1-3, pp. 302-308, 2005.

[99] J. L. Pohjoismäki, T. Boettger, Z. Liu, S. Goffart, M. Szibor, and T. Braun, "Oxidative stress during mitochondrial biogenesis compromises mtDNA integrity in growing hearts and induces a global DNA repair response," Nucleic Acids Research, vol. 40, no. 14, pp. 6595-6607, 2012.

[100] M. Falkenberg, N. G. Larsson, and C. M. Gustafsson, "DNA replication and transcription in mammalian mitochondria," Annual Review of Biochemistry, vol. 76, pp. 679-699, 2007.

[101] D. Litonin, M. Sologub, Y. Shi et al., "Human mitochondrial transcription revisited: only TFAM and TFB2M are required for transcription of the mitochondrial genes in vitro," Journal of Biological Chemistry, vol. 285, no. 24, pp. 18129-18133, 2010.

[102] Y. Matsushima, Y. Goto, and L. S. Kaguni, "Mitochondrial Lon protease regulates mitochondrial DNA copy number and transcription by selective degradation of mitochondrial transcription factor A (TFAM)," Proceedings of the National Academy of Sciences of the United States of America, vol. 107, no. 43, pp. 18410-18415, 2010.

[103] C. Kukat, C. A. Wurm, H. Spahr, M. Falkenberg, N. G. Larsson, and S. Jakobs, "Super-resolution microscopy reveals that mammalian mitochondrial nucleoids have a uniform size and frequently contain a single copy of mtDNA," Proceedings of the National Academy of Sciences of the United States of America, vol. 108, no. 33, pp. 13534-13539, 2011.

[104] G. Attardi and G. Schatz, "Biogenesis of mitochondria," Annual Review of Cell Biology, vol. 4, pp. 289-333, 1988. 


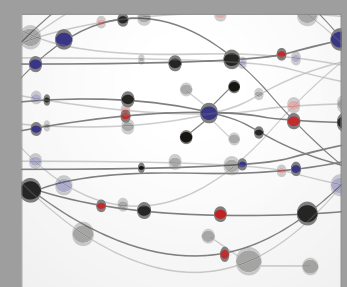

The Scientific World Journal
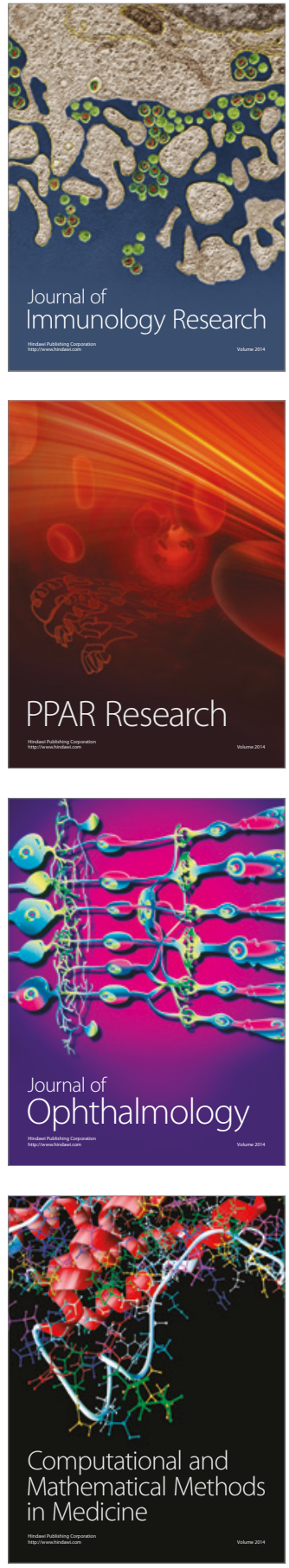

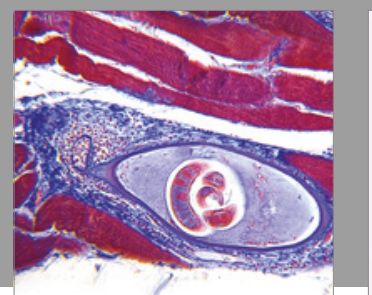

Gastroenterology Research and Practice
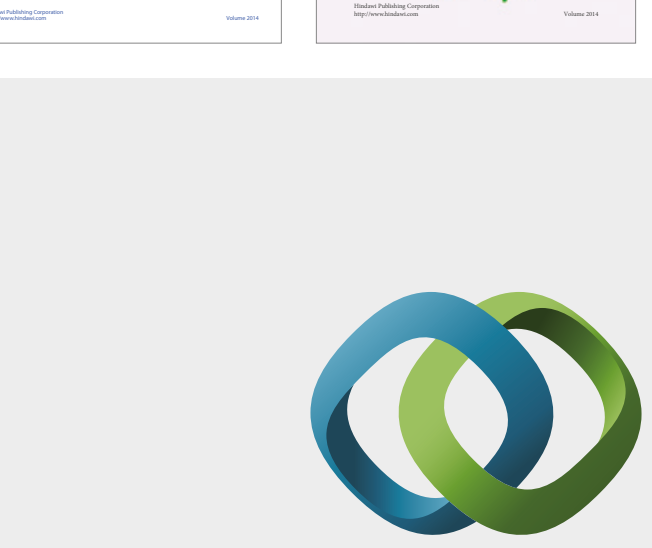

\section{Hindawi}

Submit your manuscripts at

https://www.hindawi.com
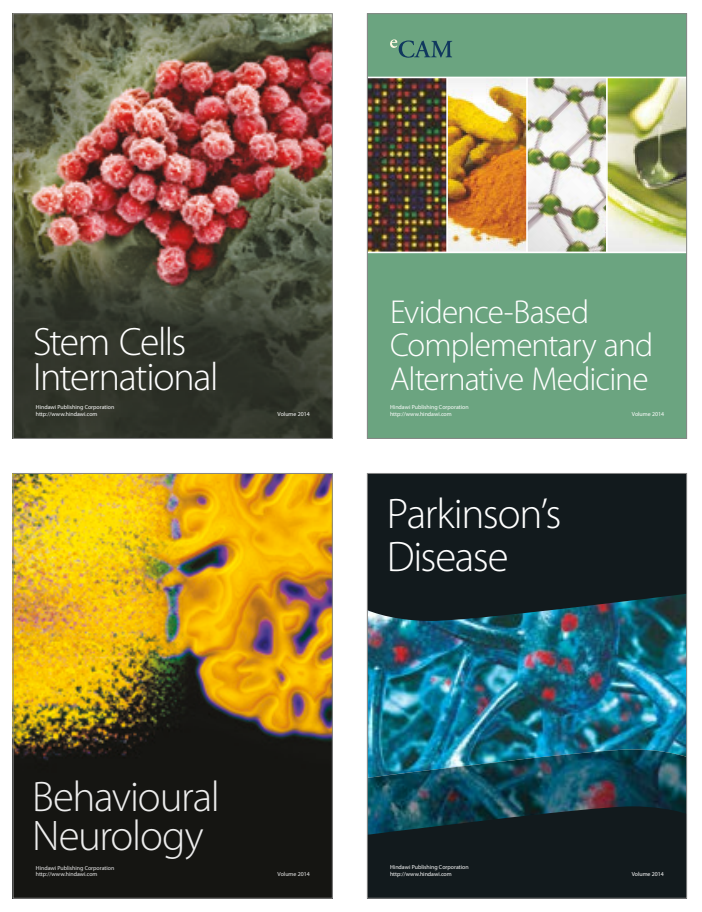
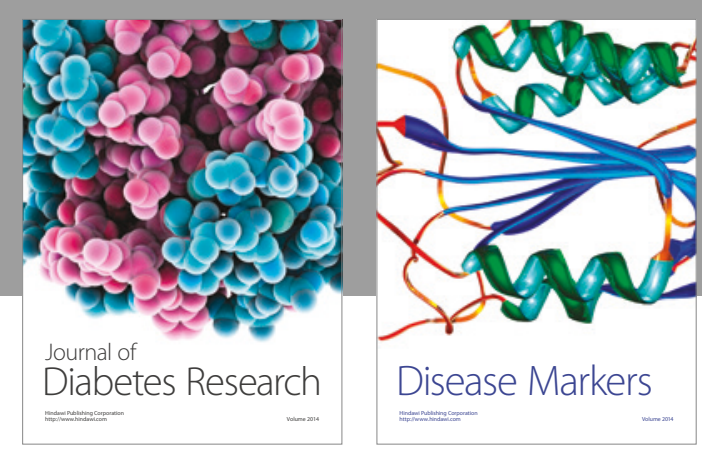

Disease Markers
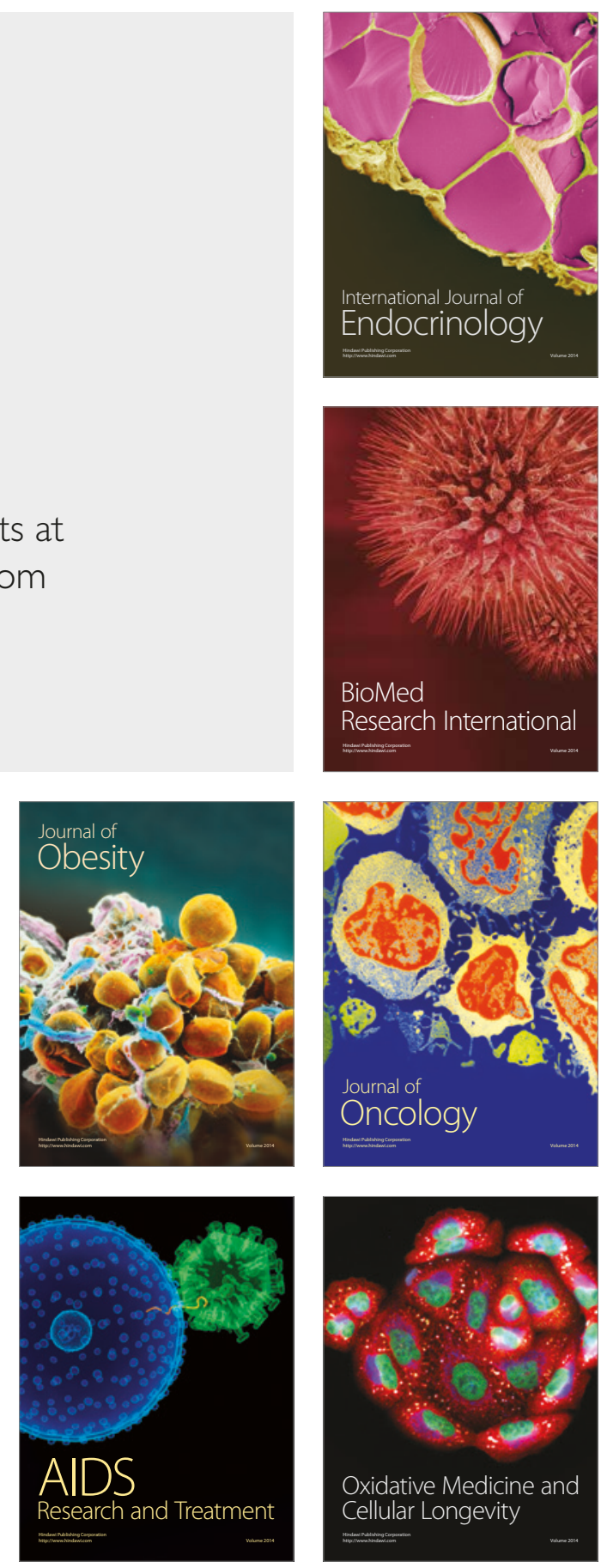